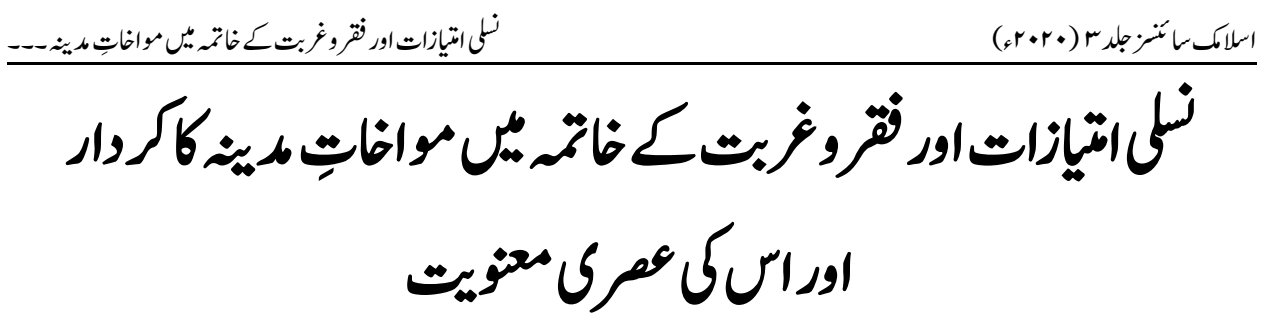

\title{
Role of Madinah's Brotherhood in eliminating poverty and racial discriminations: A study based on its importance in current scenario
}

$$
\begin{aligned}
& \text { مبثر }
\end{aligned}
$$

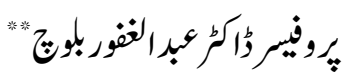

$$
\begin{aligned}
& \text { كتث ثير" }
\end{aligned}
$$

\begin{abstract}
:
The life of Prophet Muhammad (peace be upon him) is the best example for humanity. The success of humanity is in obedience of Hazrat Muhammad (peace be upon him). He gave guidance for individual and collective life. He took ideal steps for the improvement of society and for the elimination of poverty and prejudices. In such steps, the most remarkable one is the Madinah's brotherhood. Hazrat Muhammad (peace be upon him) created brotherhood among migrants and resident of Madinah by calling the name of one migrant (Muhajir) and one resident (Ansar) and declared them to be brothers of each other like the real brothers. As a result of this agreement, poverty and prejudices were eradicated from the society. The refugees got permanent residence and their food and drink were arranged. The paper presents this brotherhood as perfect model to be followed by the societies to overcome the issues of poverty and racial discriminations.
\end{abstract}

Keywords: Muakhat, Madina, poverty, prejudice, refugees, brotherhood, discrimination, Islam

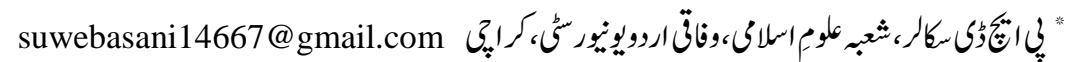

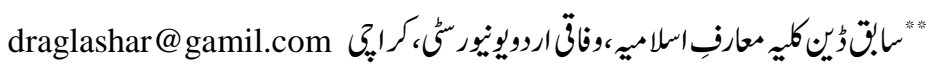

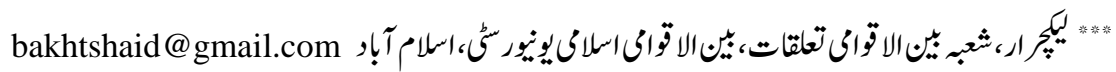




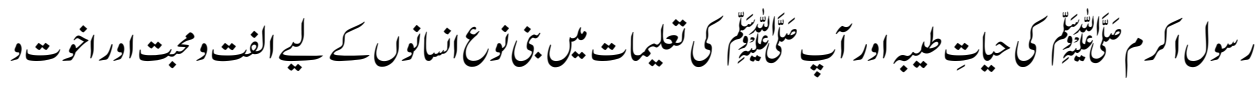

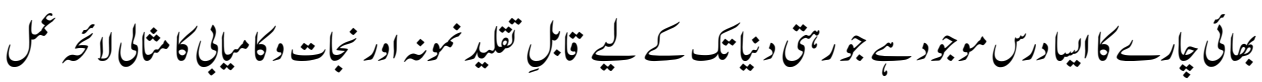

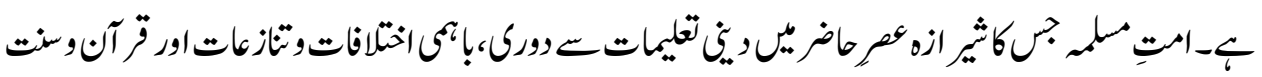

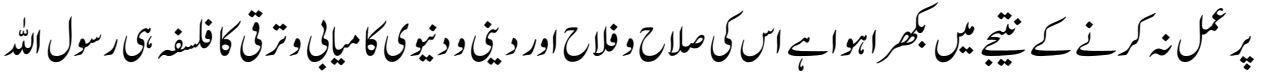

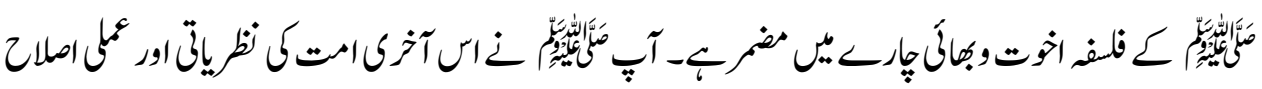

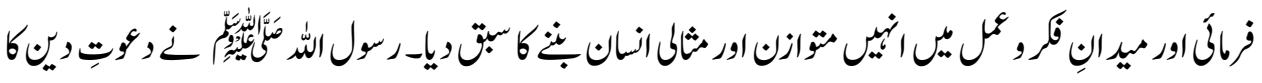

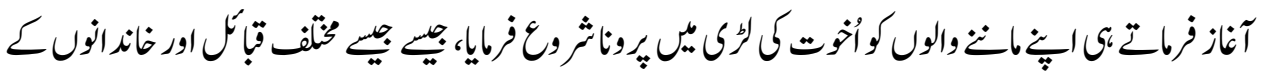

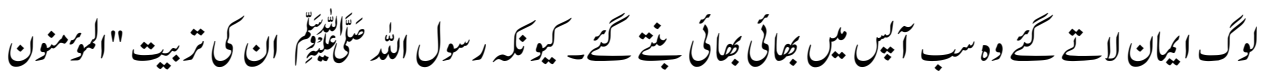

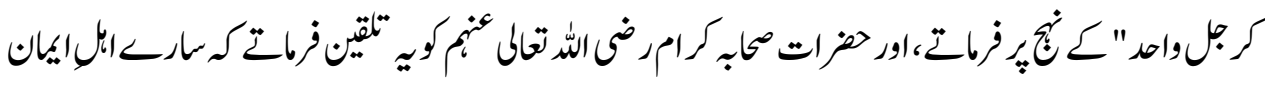

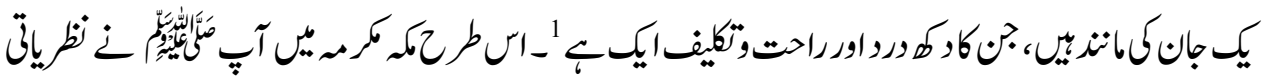

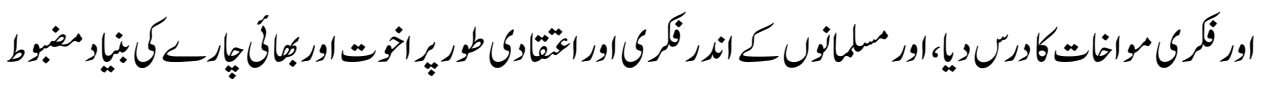

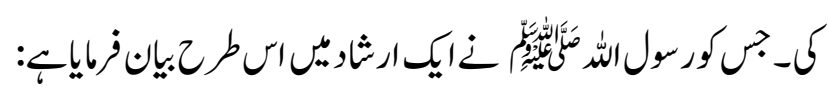

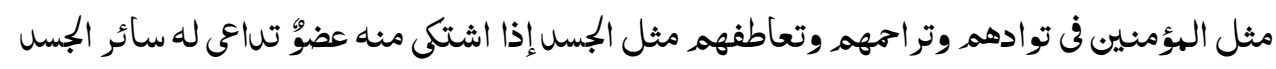

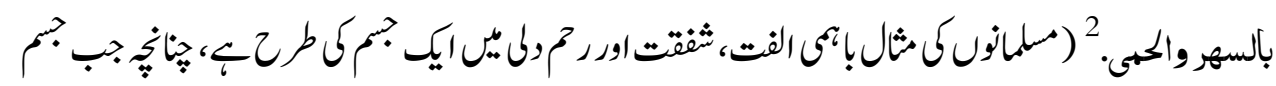

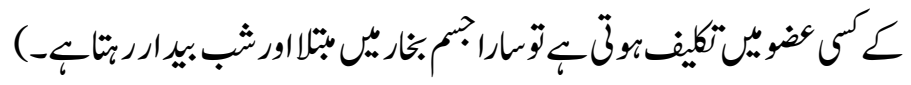

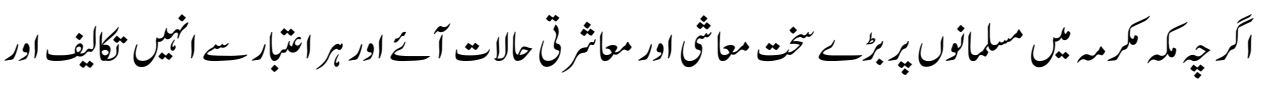

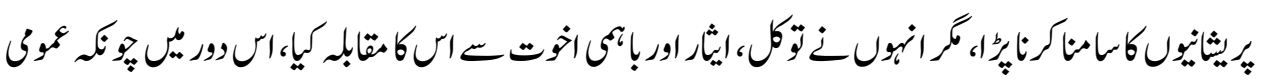

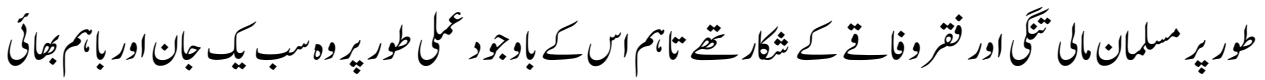

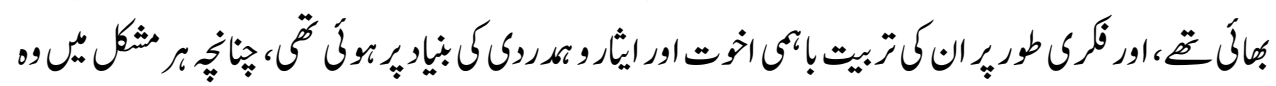

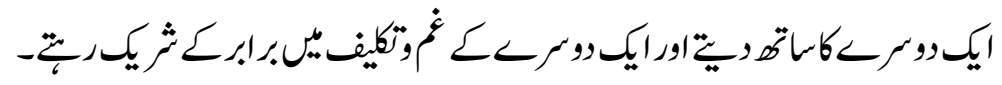

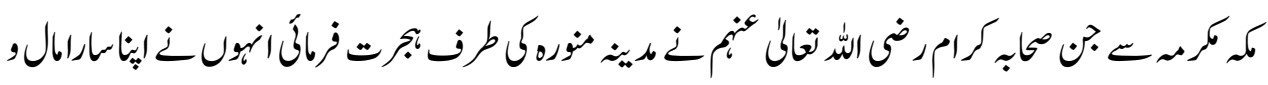

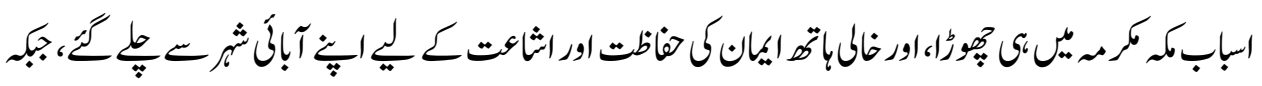

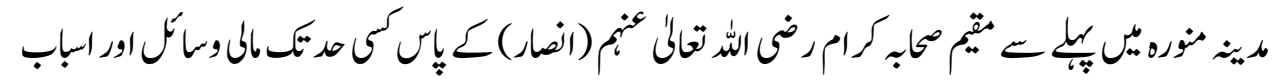




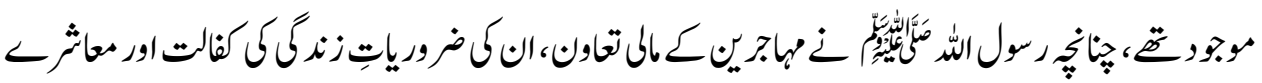

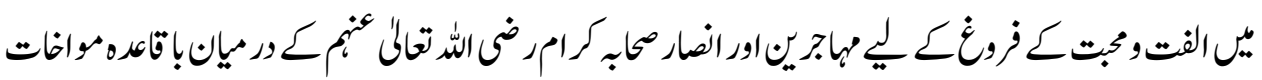

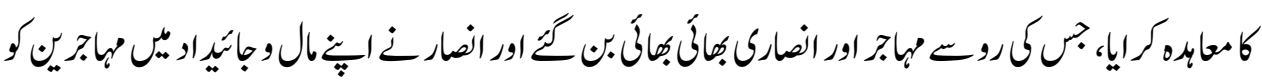

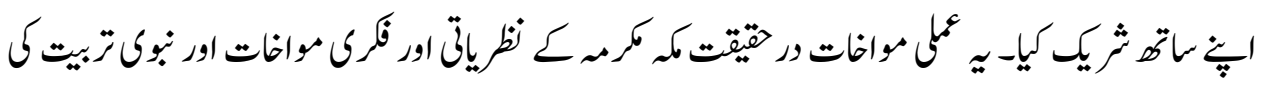

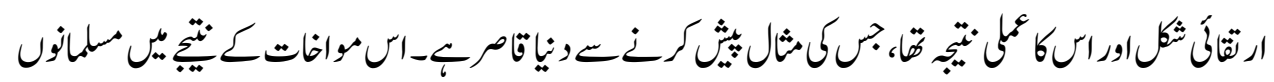

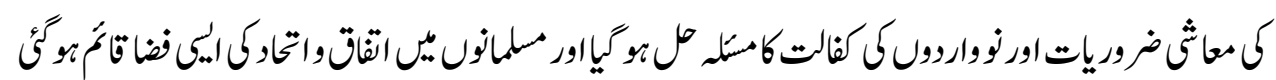

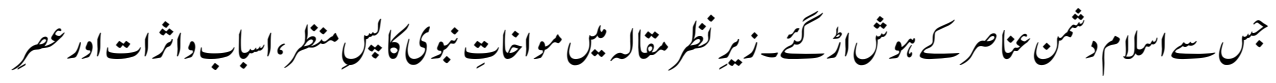

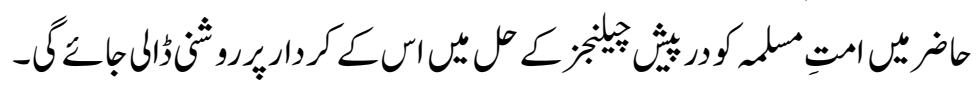
مواخات:

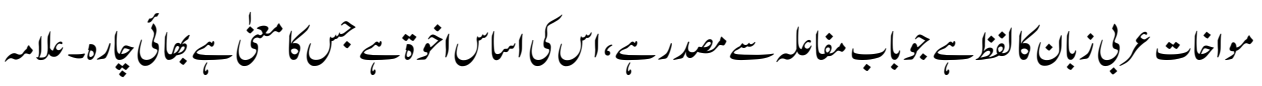

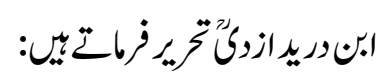

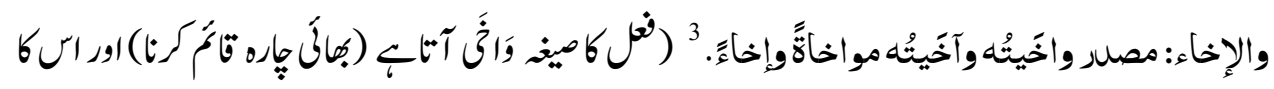

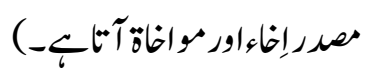

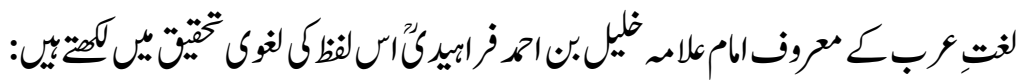

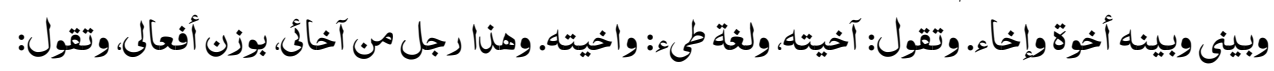

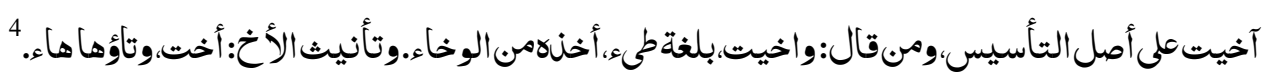

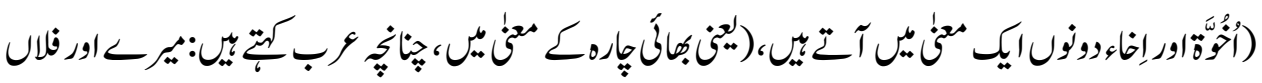

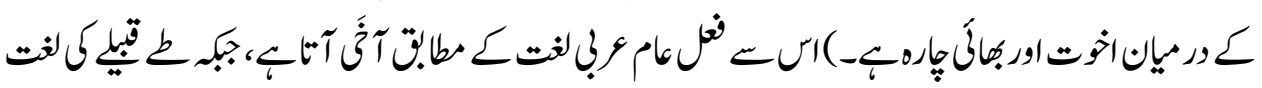

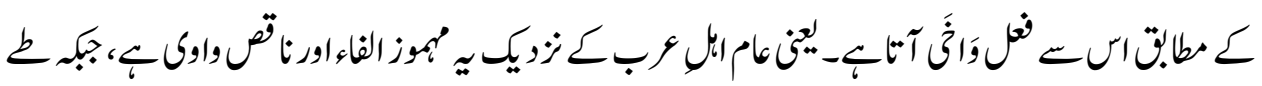

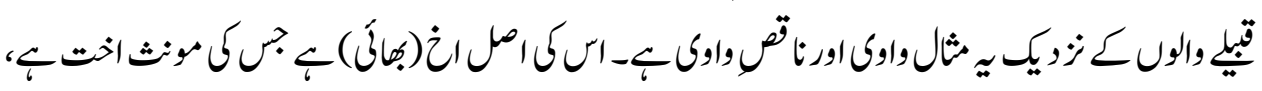

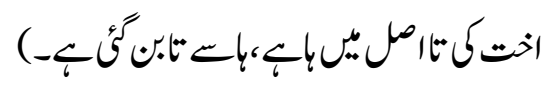

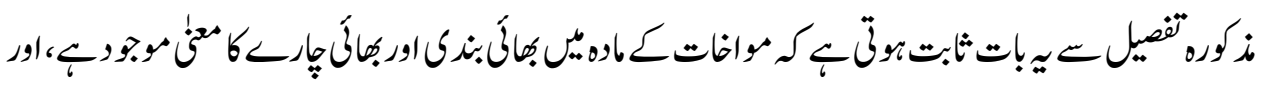

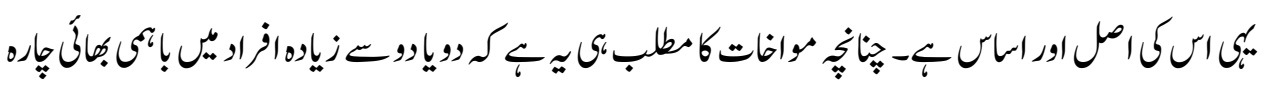




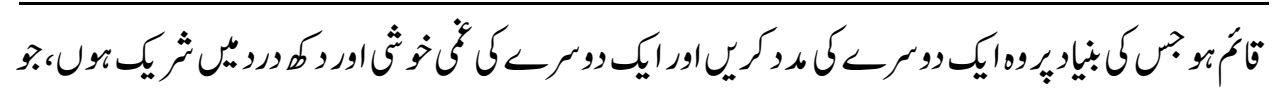

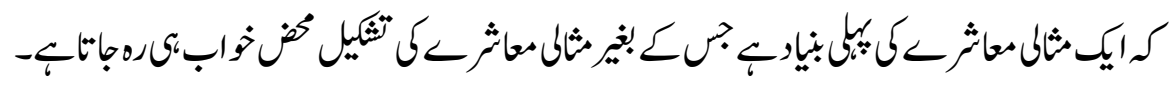

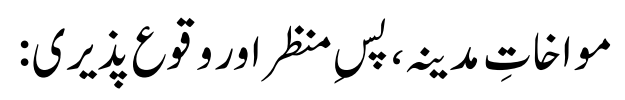

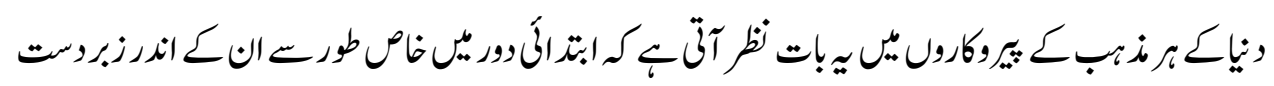

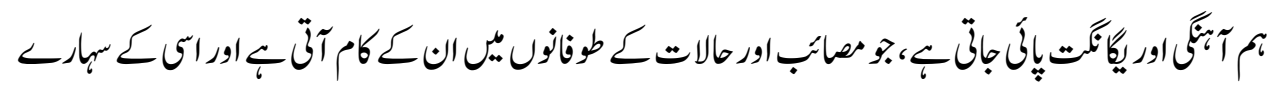

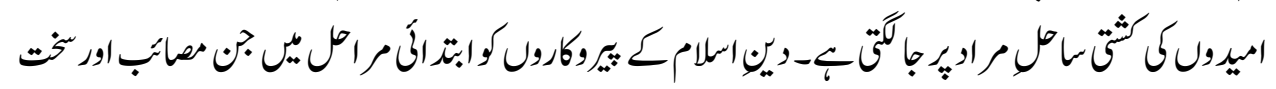

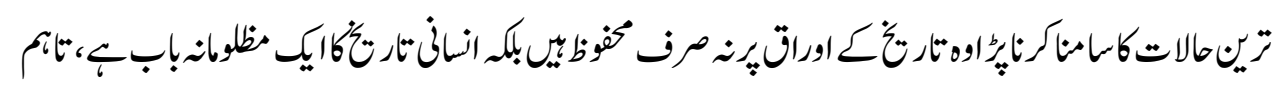

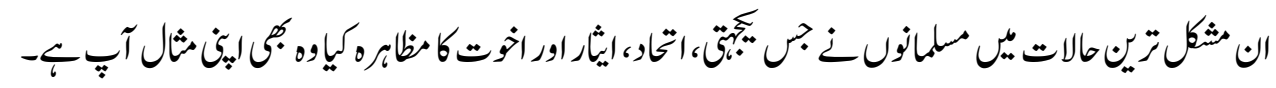

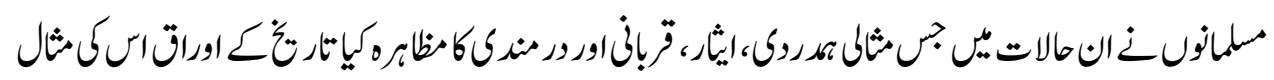

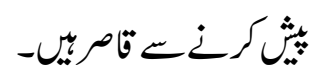

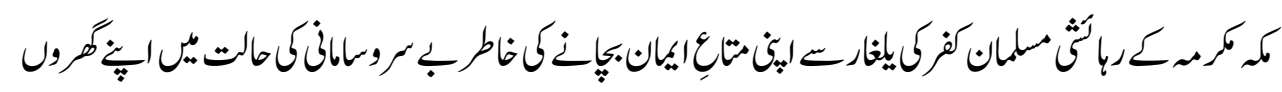

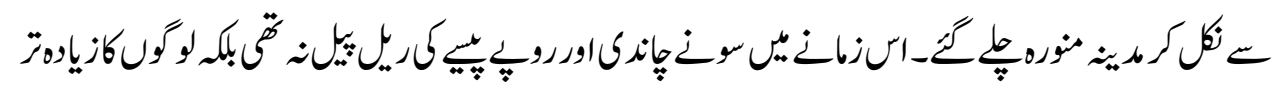

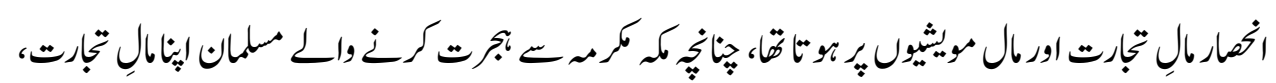

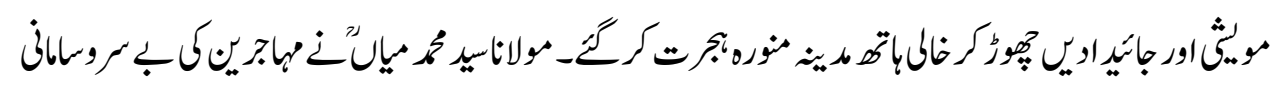

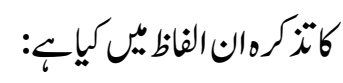

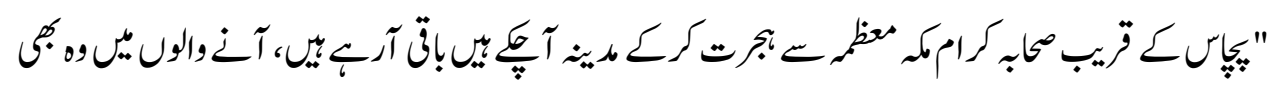

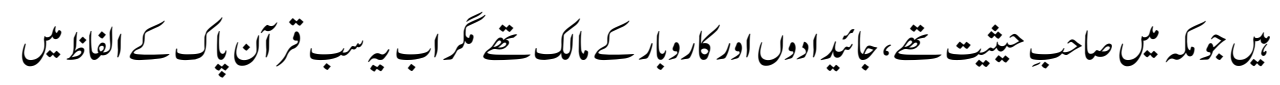

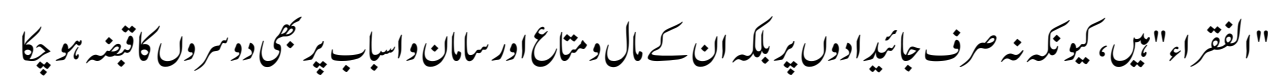

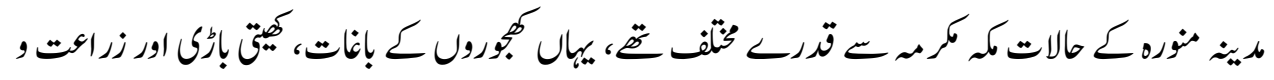

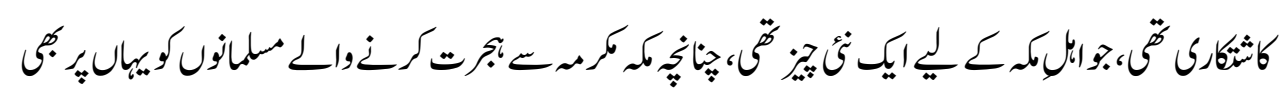

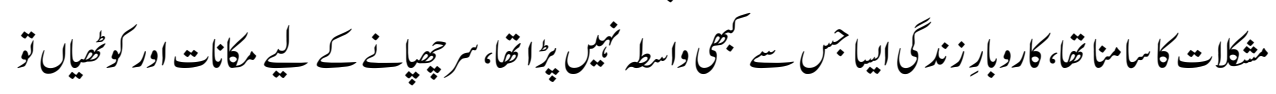

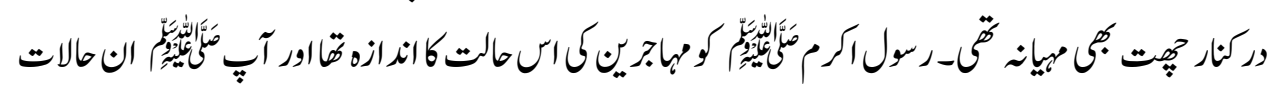




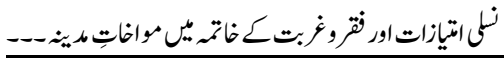

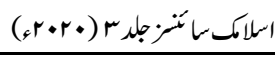

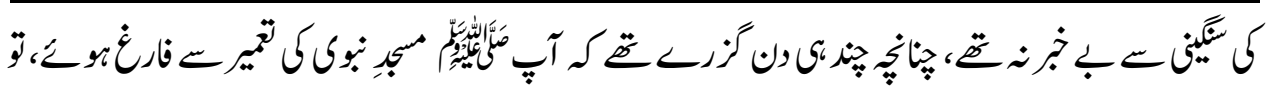

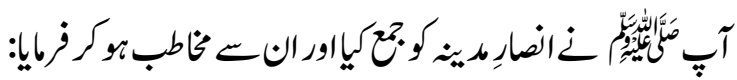

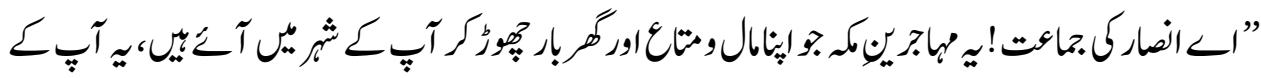

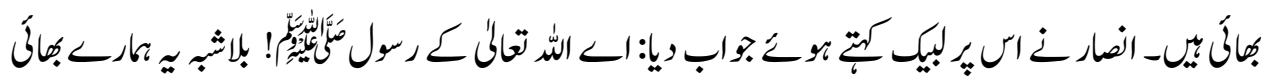

“"

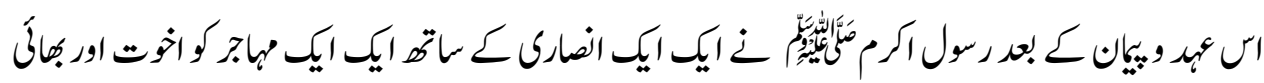

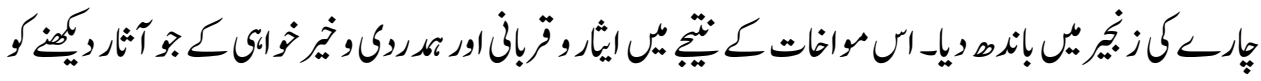

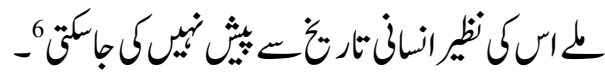

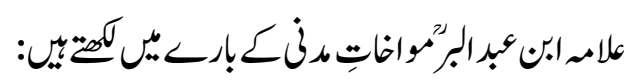

وآخى رسول الله صلى الله عليه وسلم بعل بنائه الهسجب بين الأنصار والههاجرين. وقن قيل إن الهؤاخاة

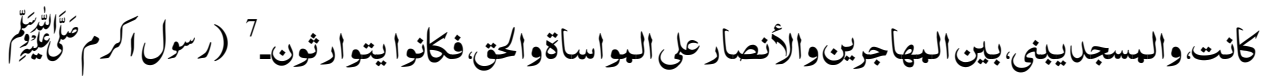

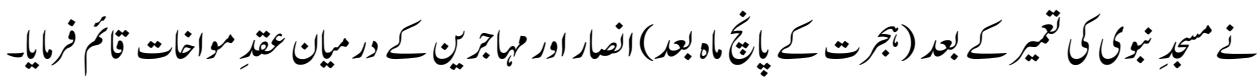

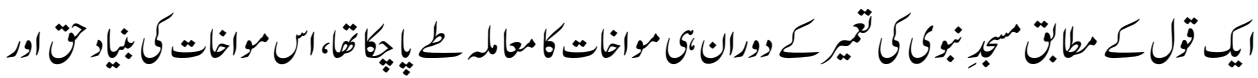

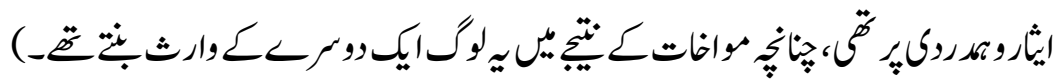

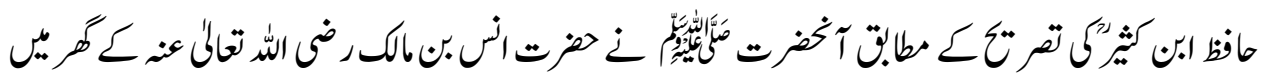

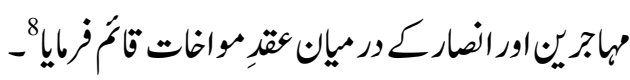

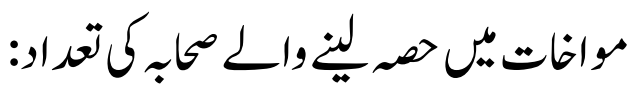

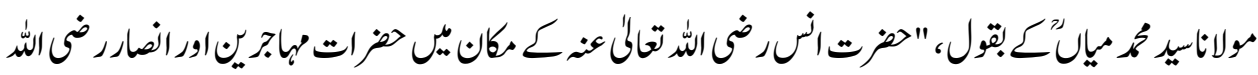

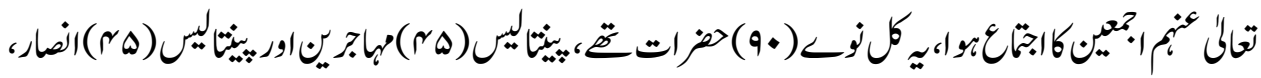

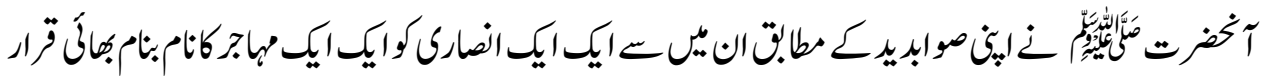

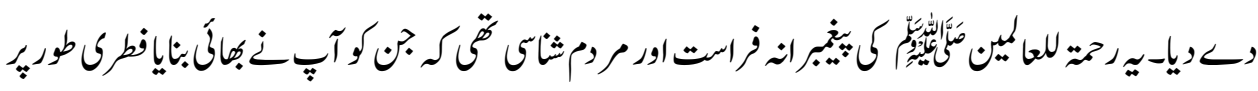

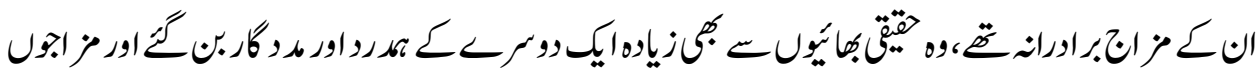

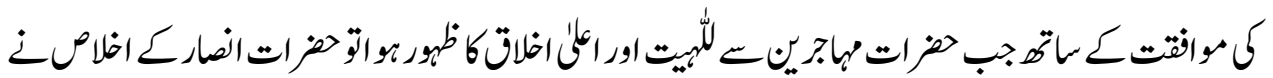

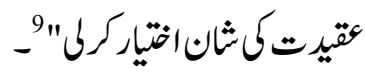

195 


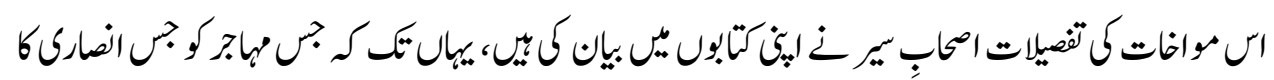

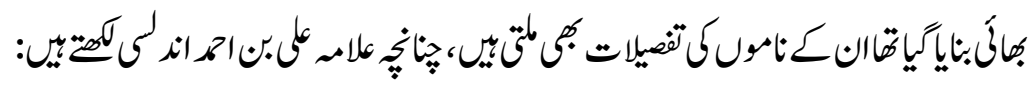

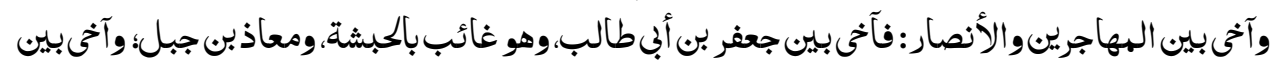

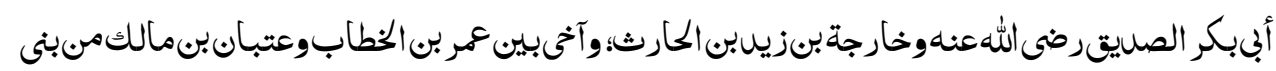

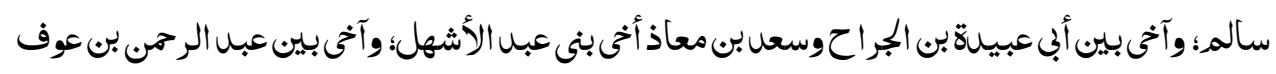

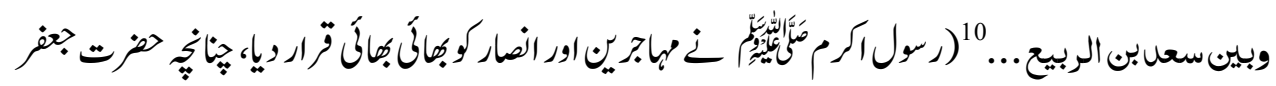

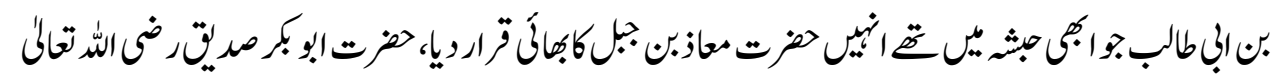

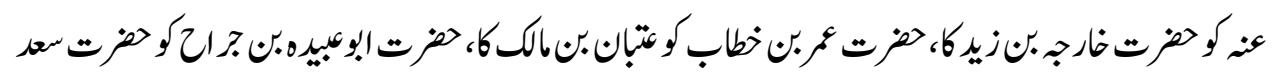

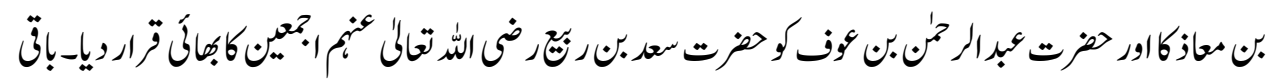

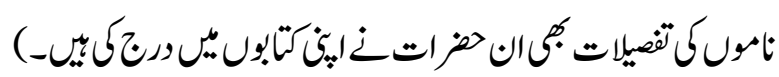

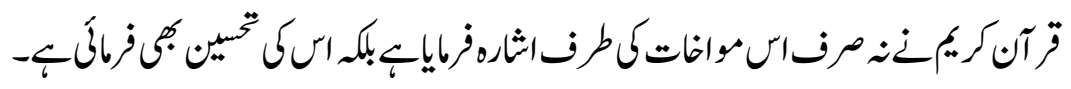

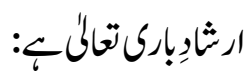

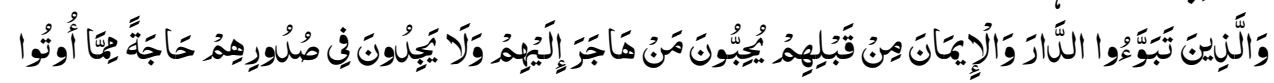

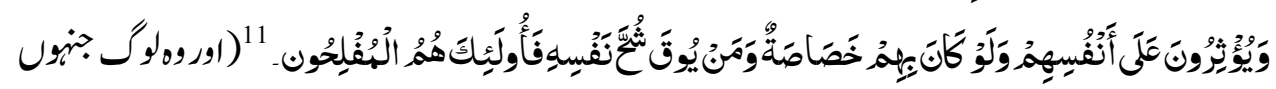

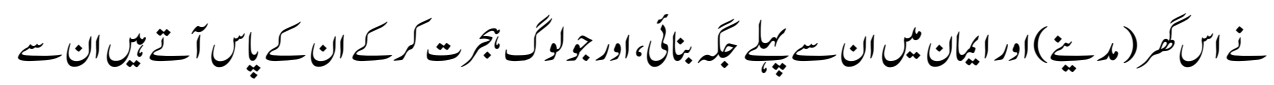

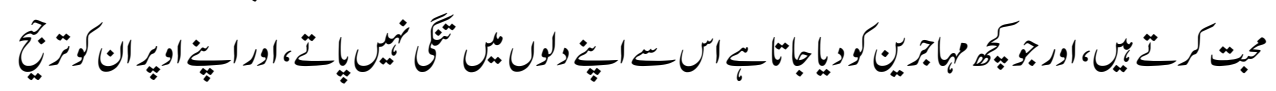

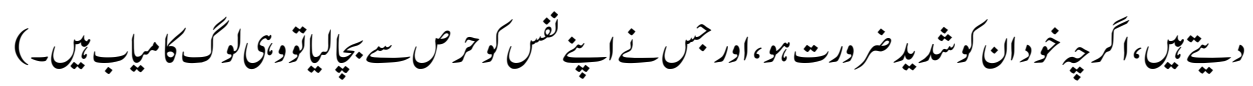

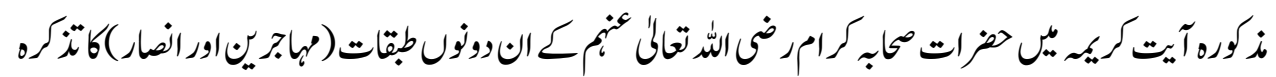

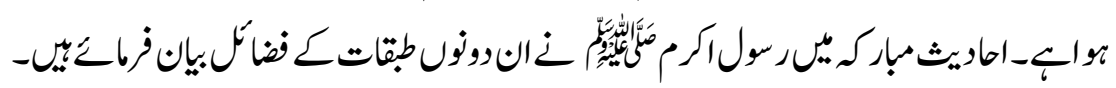
مواخاتِ مينيخ ع آثنار:

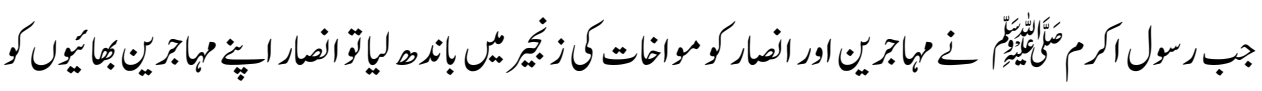

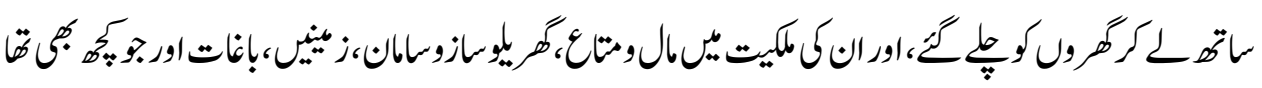

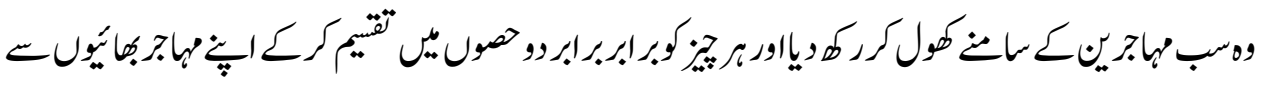




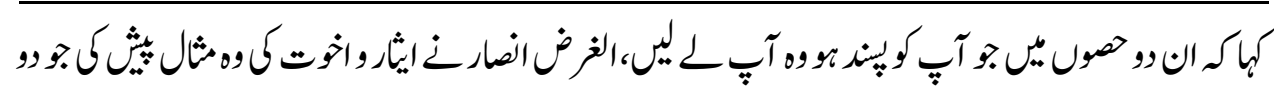

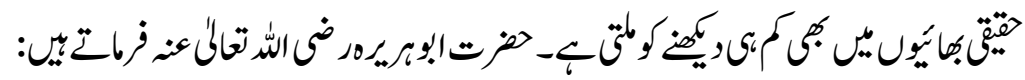

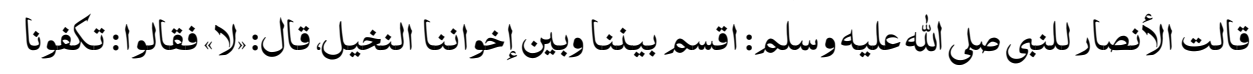

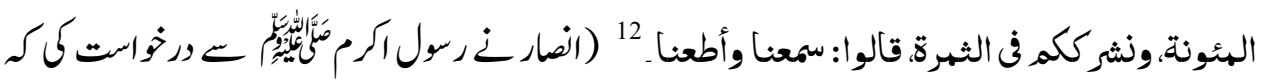

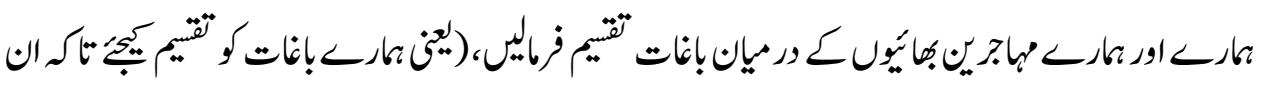

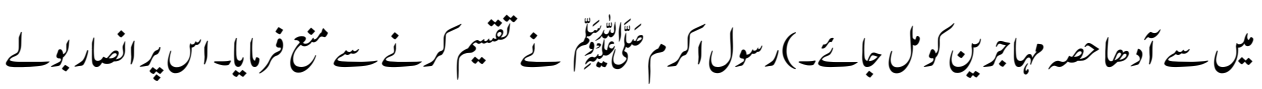

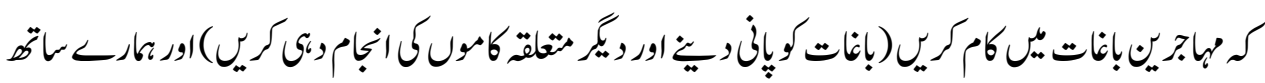

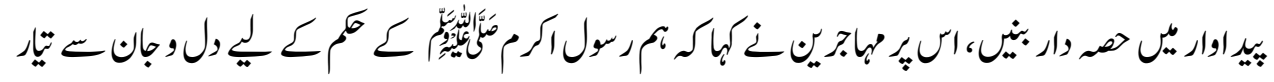

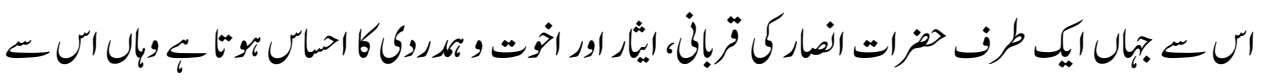

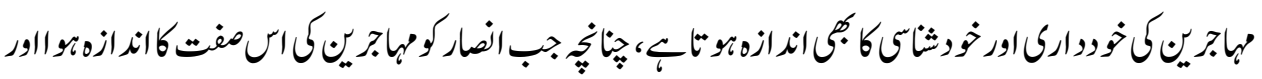

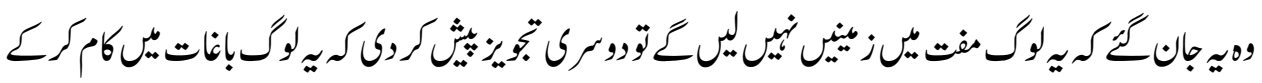

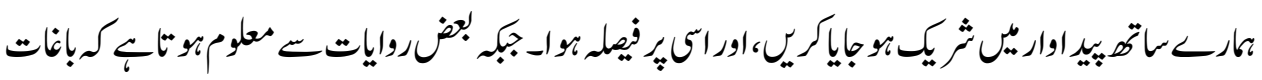

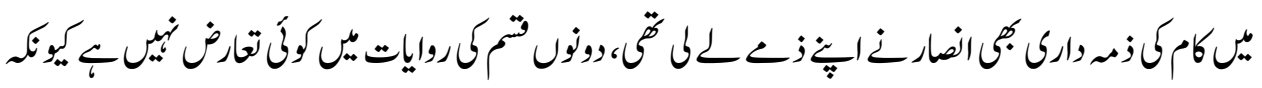

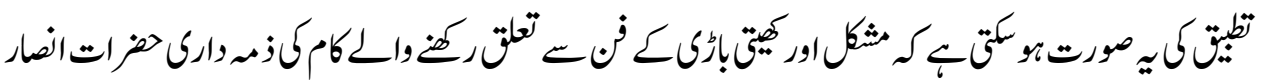

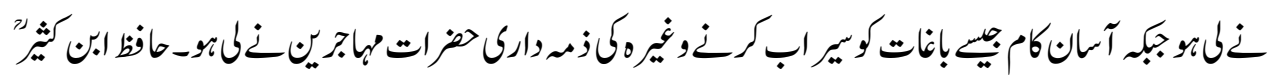
كالفاظي مئي: وقال عبل الرحم بن زيسبن أسله : قال رسول الله صلى الله عليهوسلم للأنصار " "إن إخوانكم قد تركوا

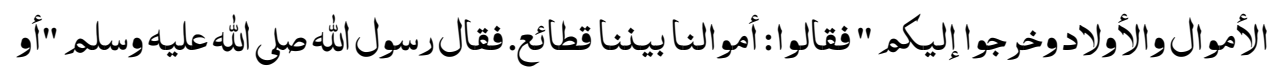

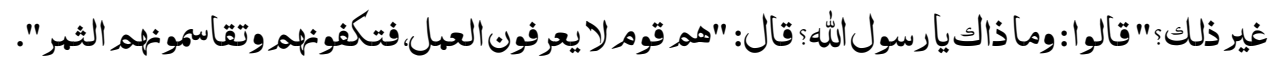

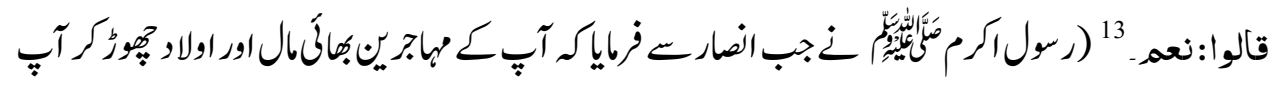

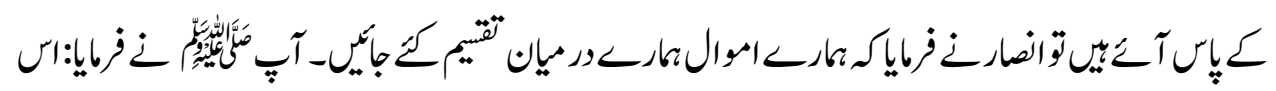

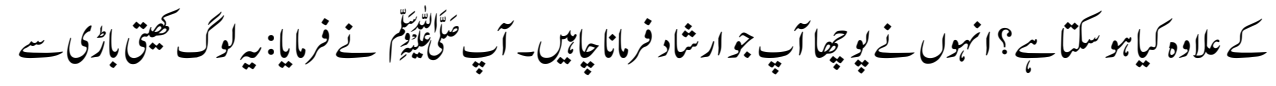

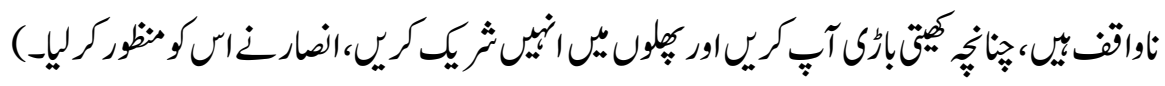




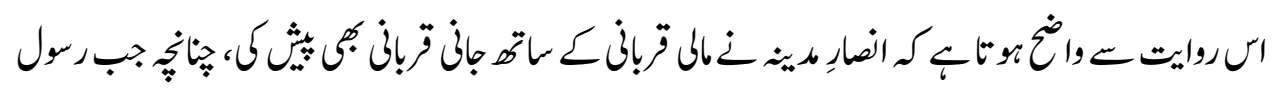

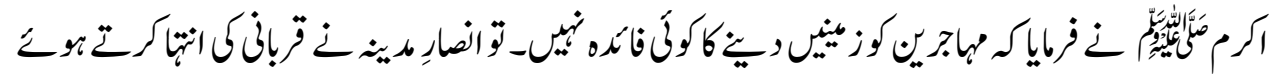

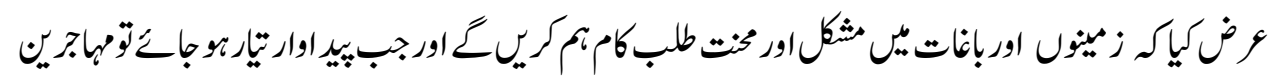

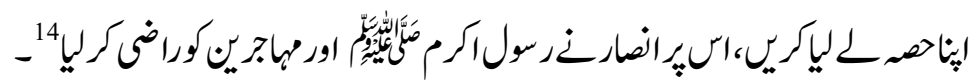

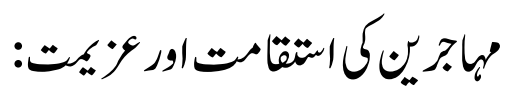

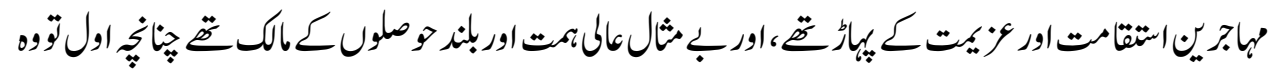

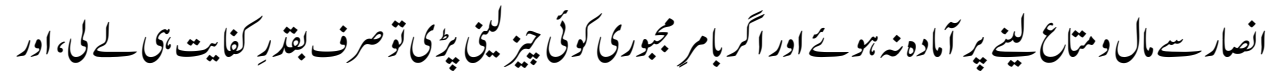

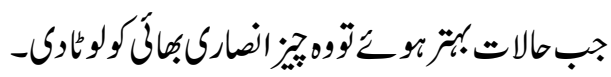

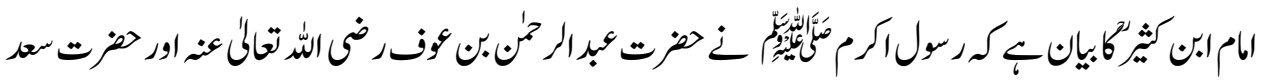

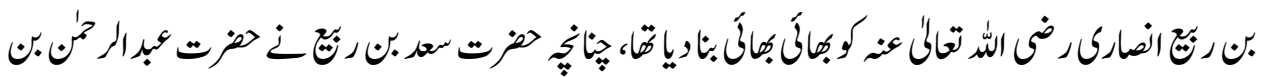

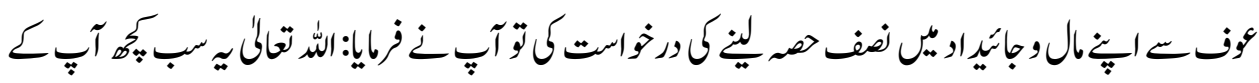

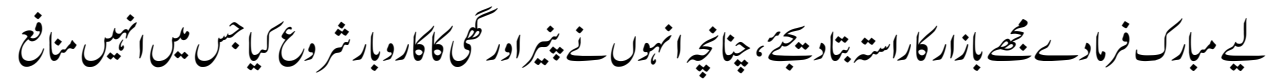

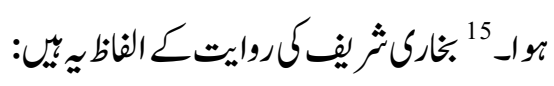

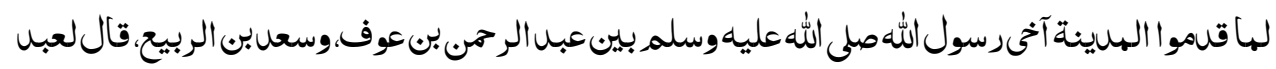

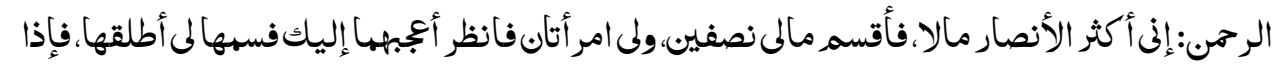

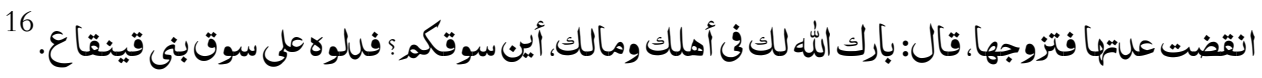

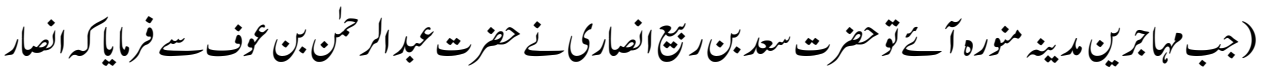

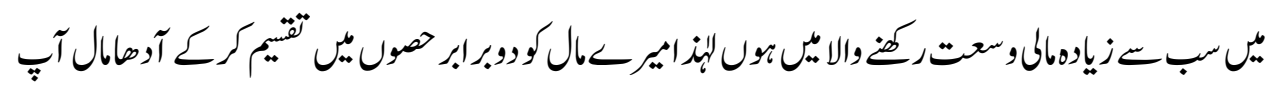

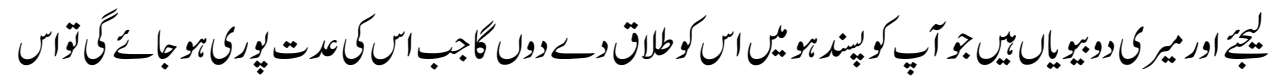

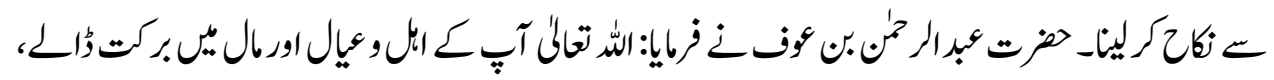

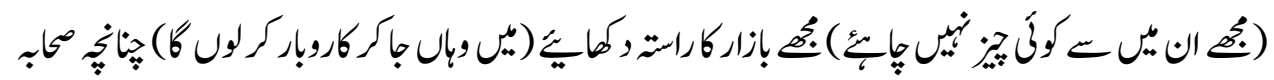

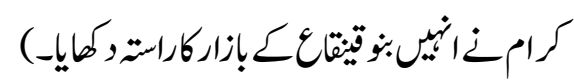




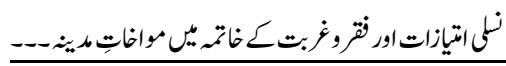

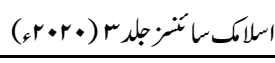

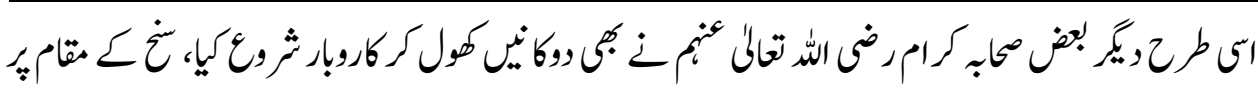

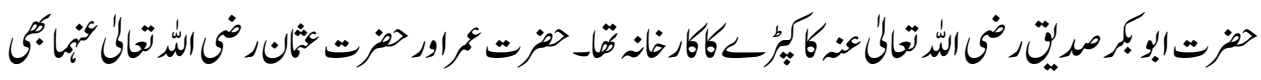

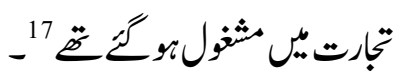

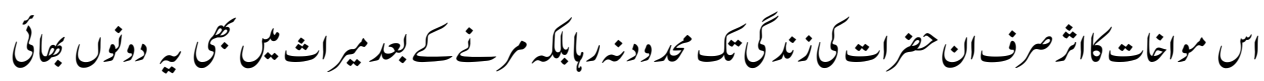

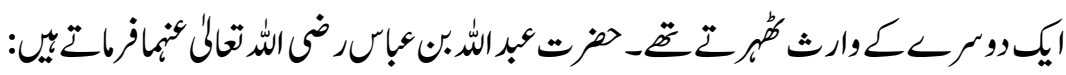

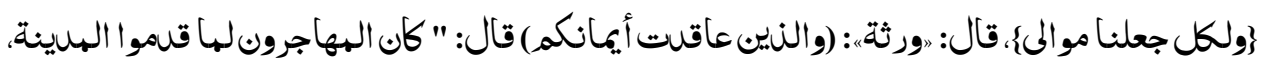

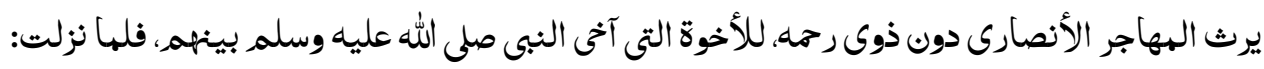

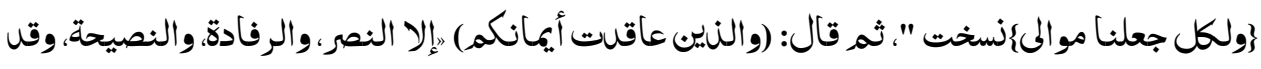

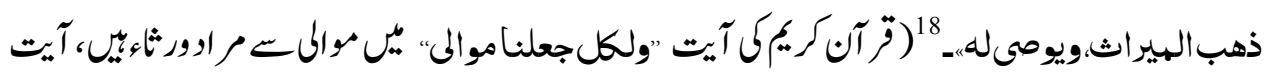

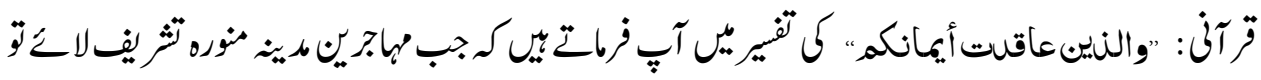

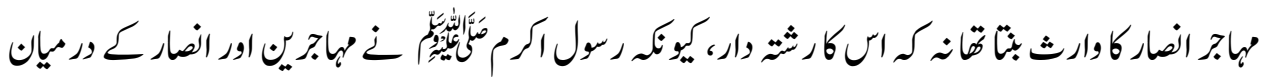

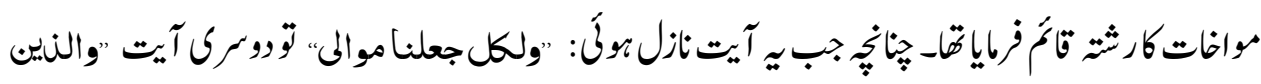

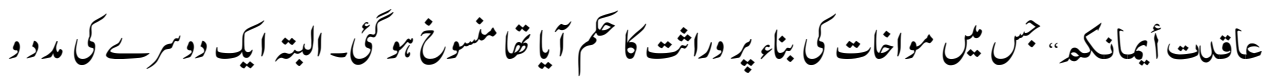

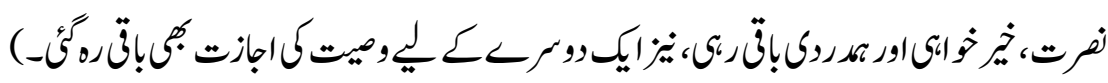

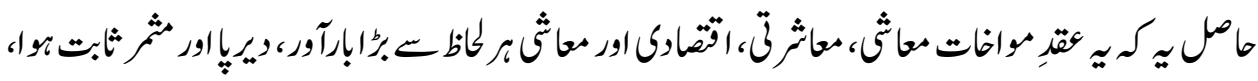

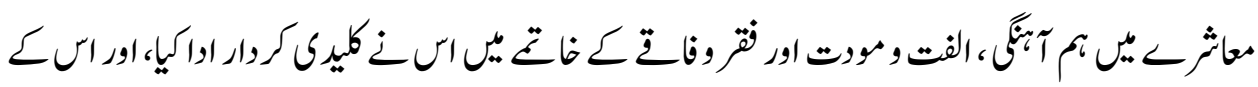

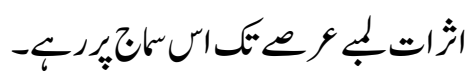

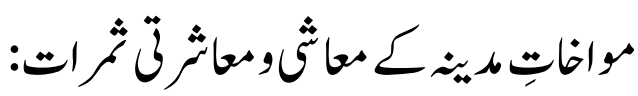

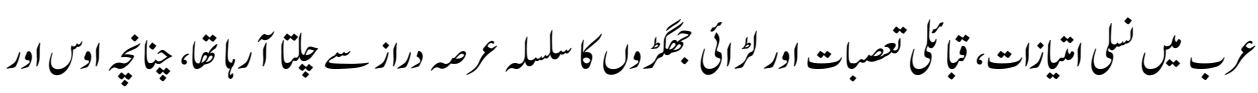

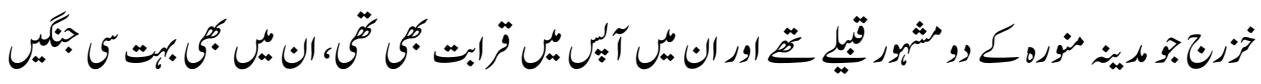

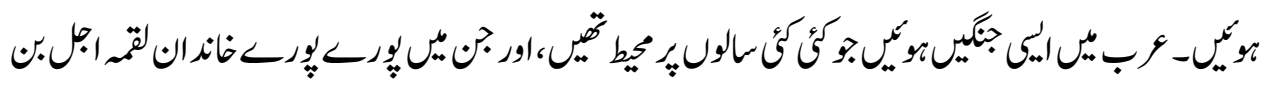

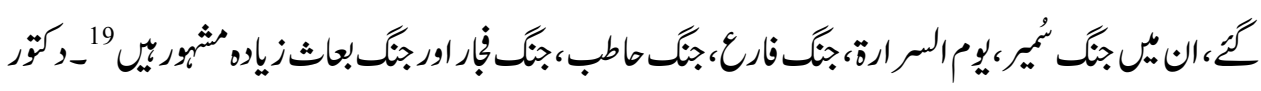

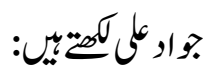

199 


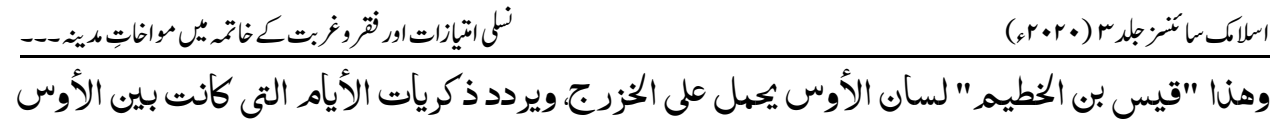

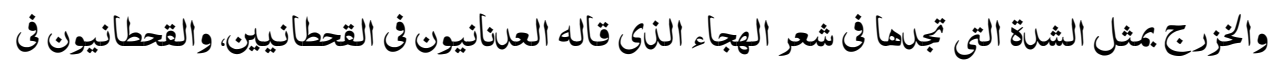
العنانييين. إنه ذكر تلك الأيام لا لهجرد الفخر والتباهى، بل ليثير في نفوس الأوس الفئ الأحقاد القنيمة.

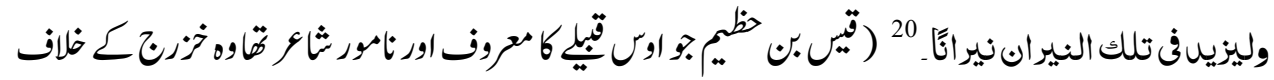

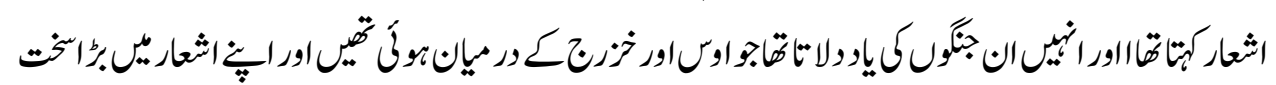

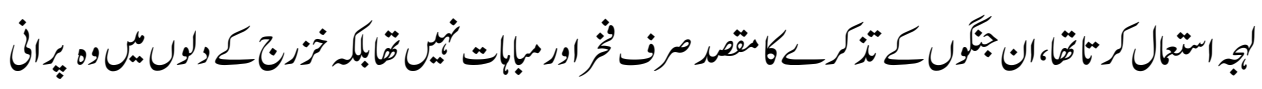

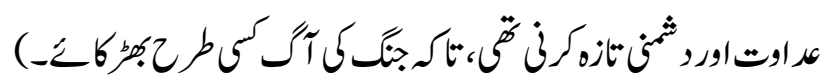

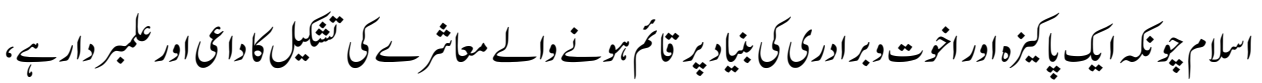

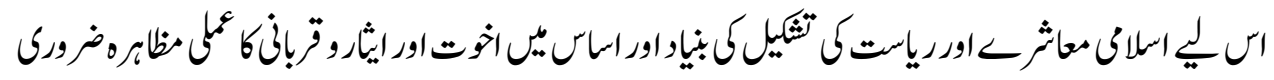

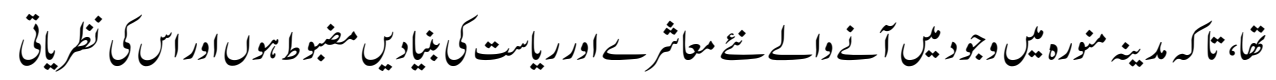

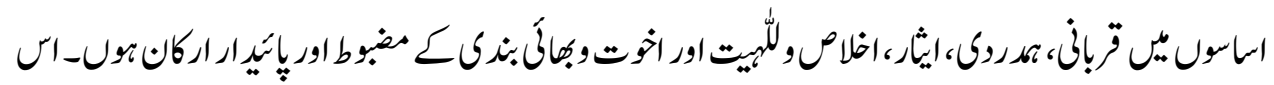

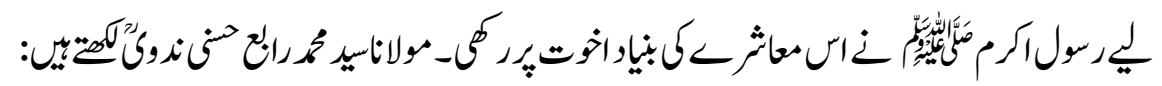

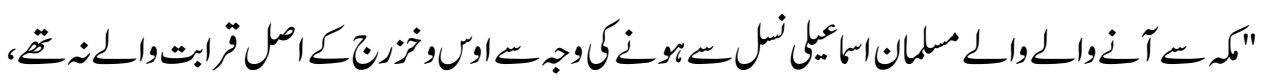

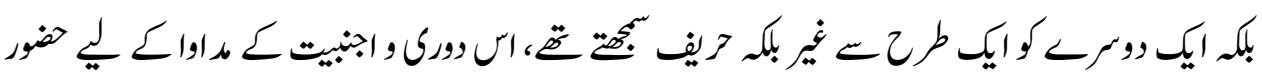

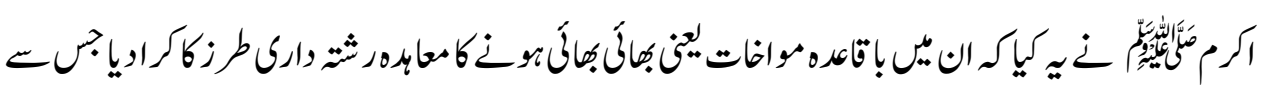

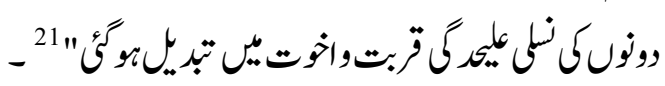

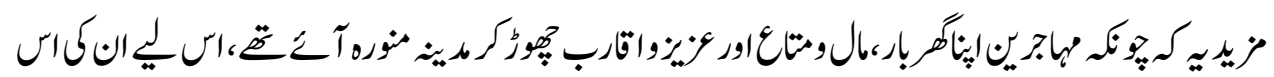

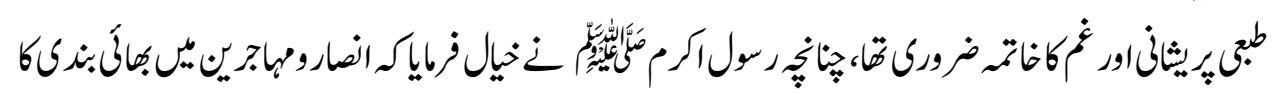

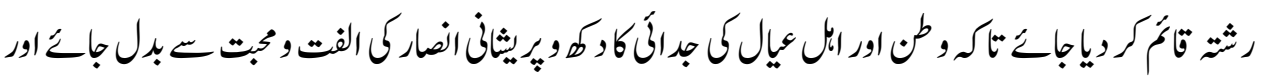

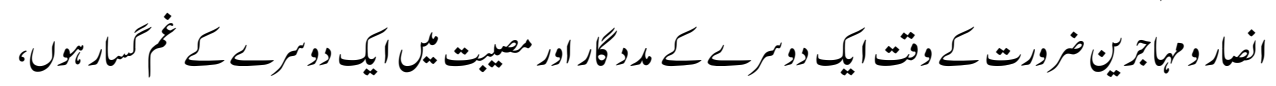

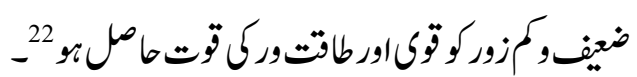

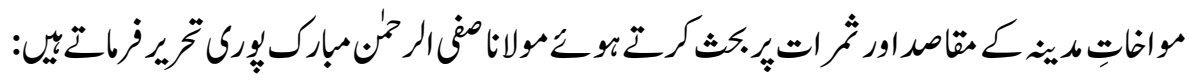

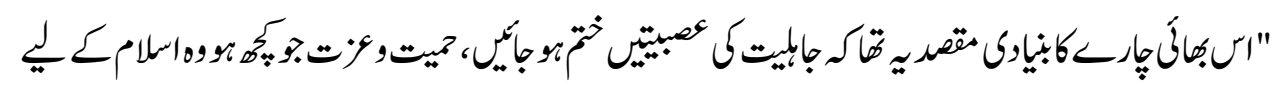

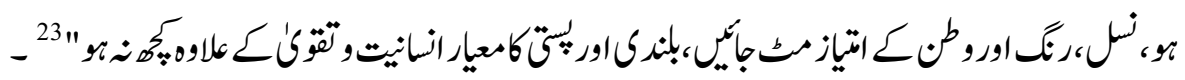




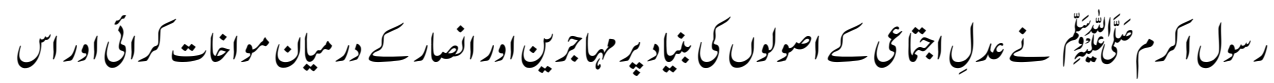

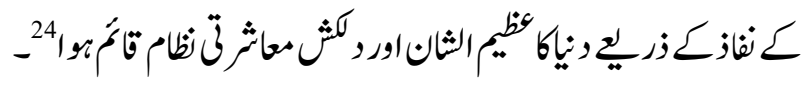

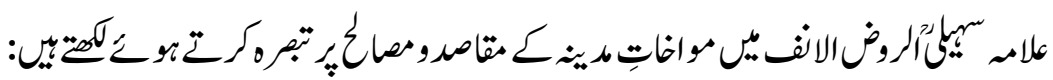

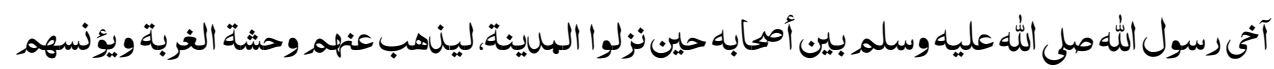

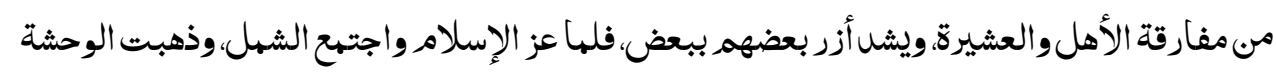

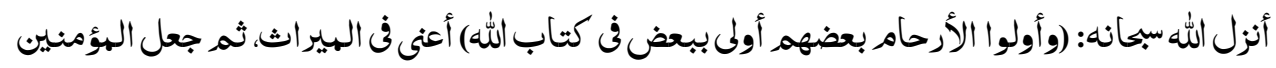

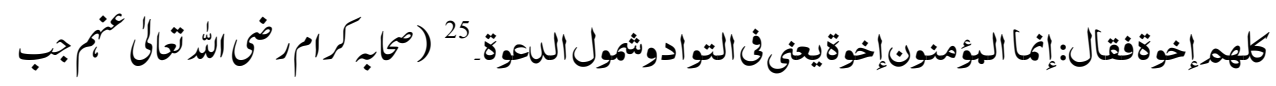

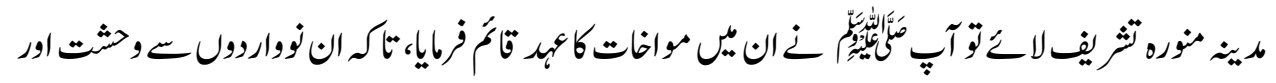

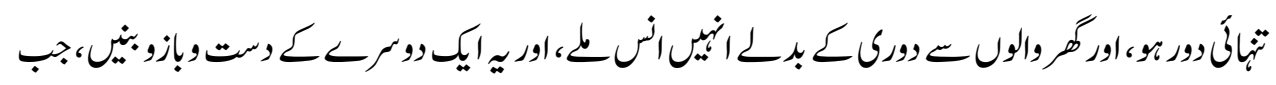

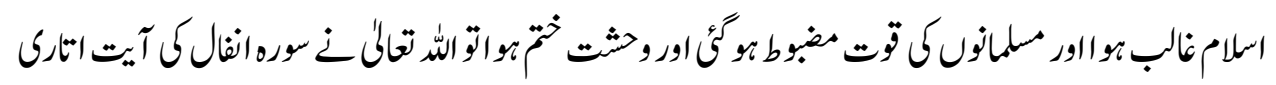

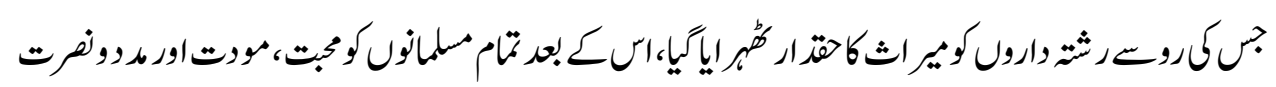

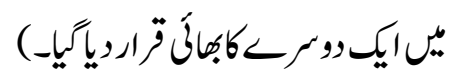

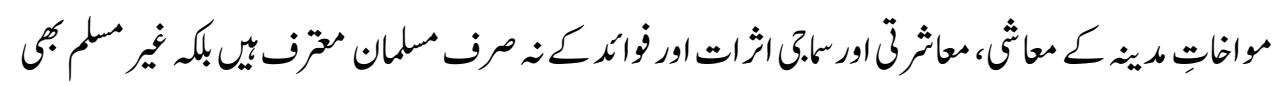

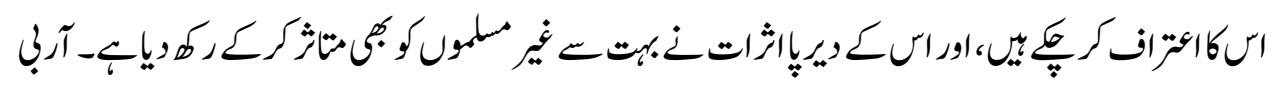

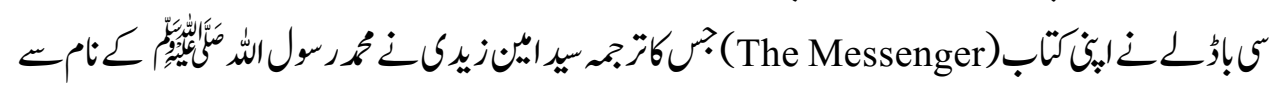

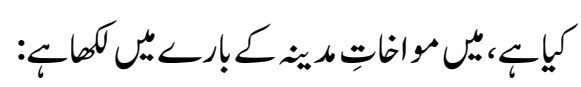

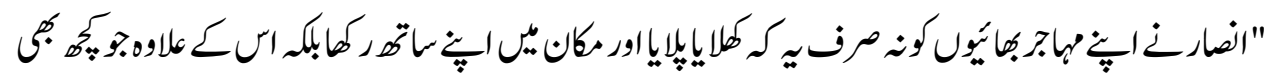

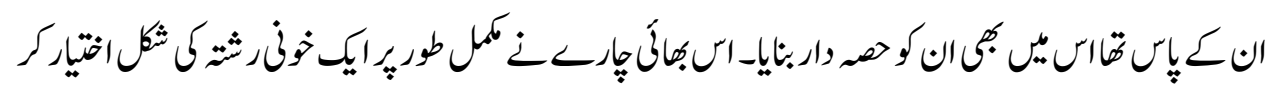

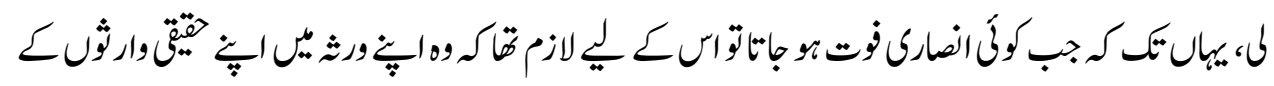

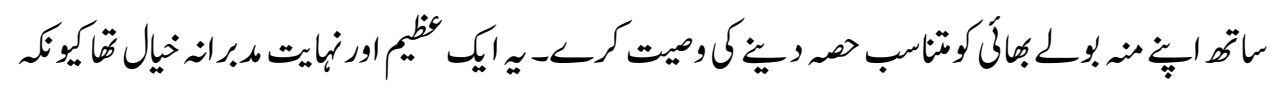

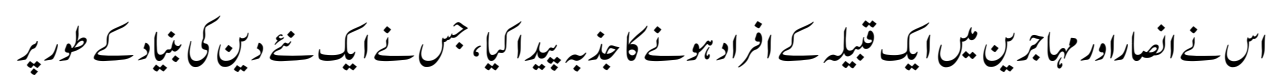

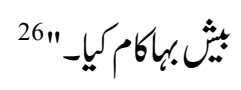

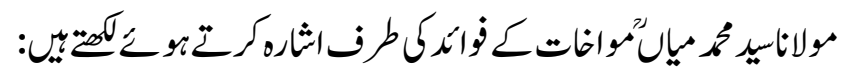




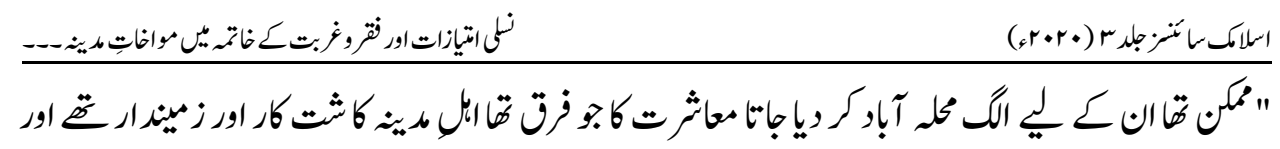

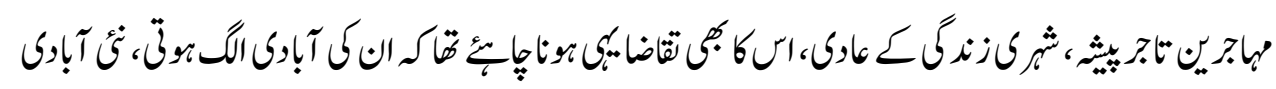

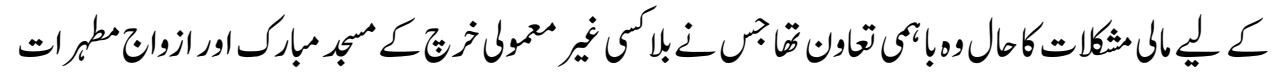

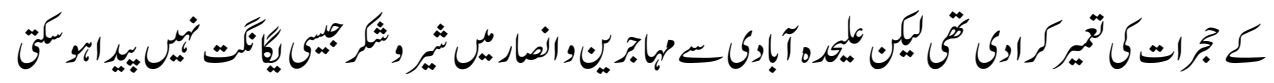

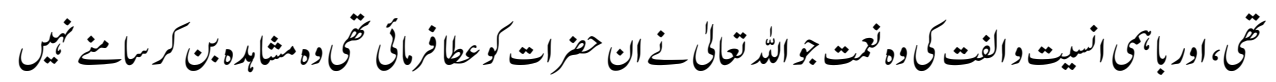

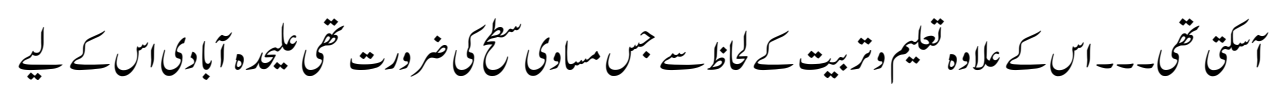

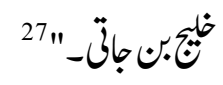

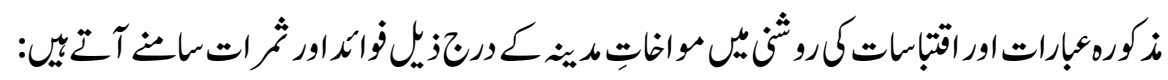

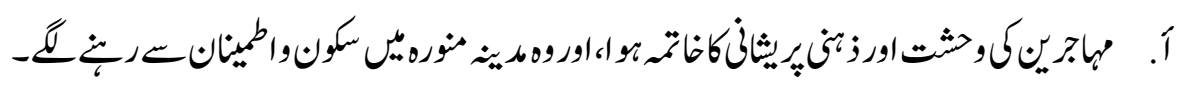

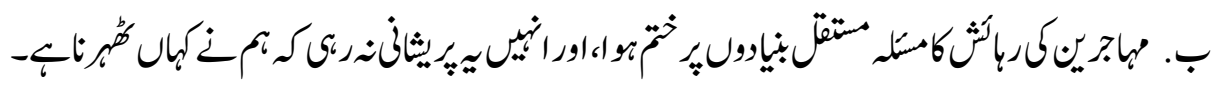

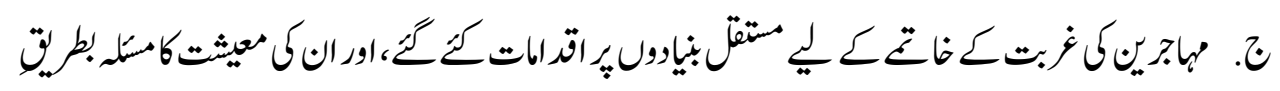

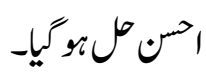

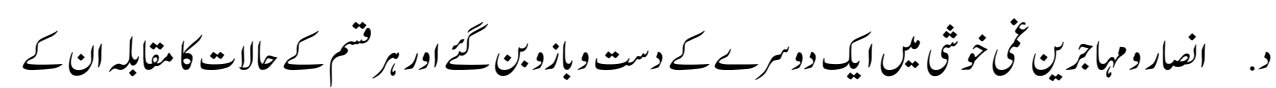

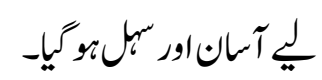

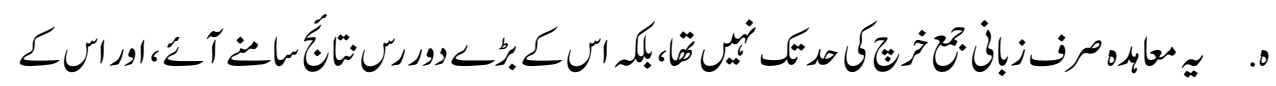

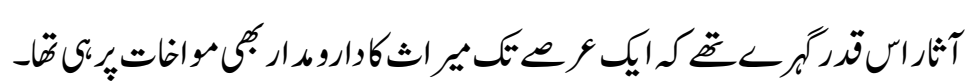

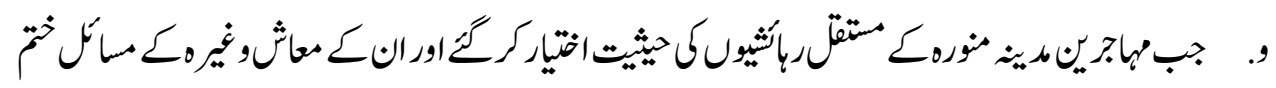

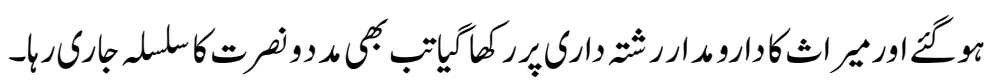

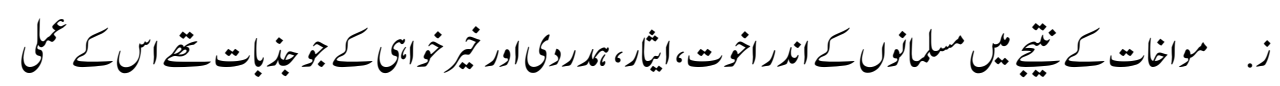

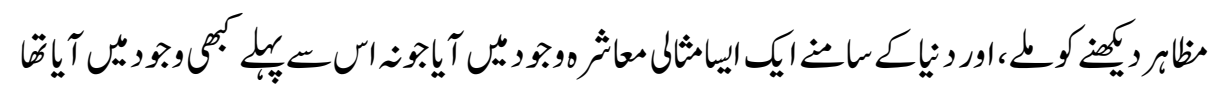

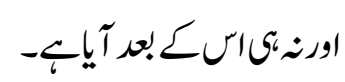

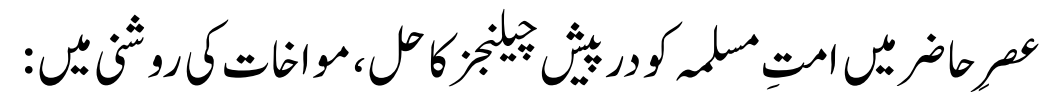




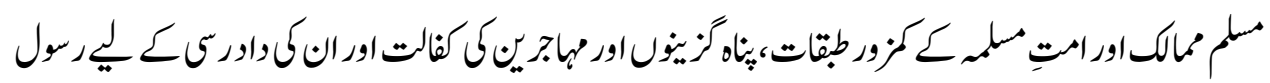

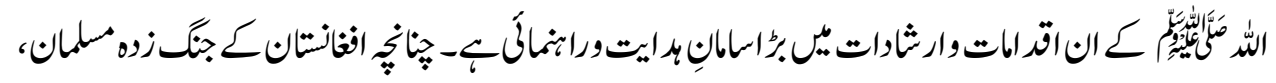

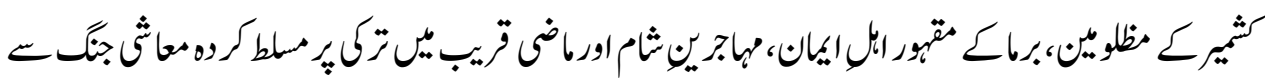

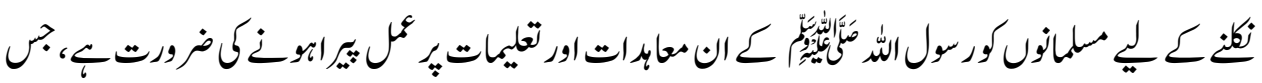

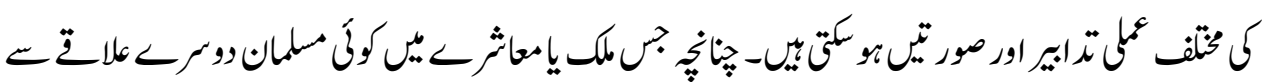

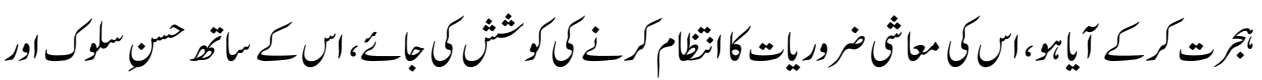

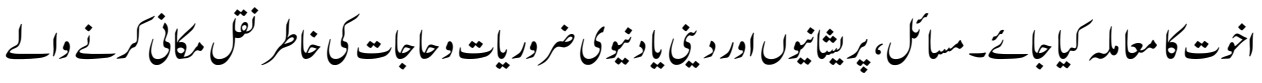

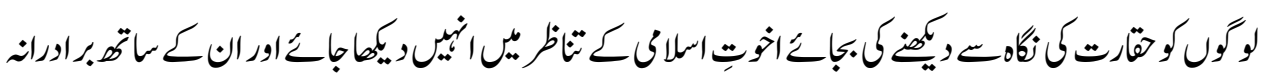

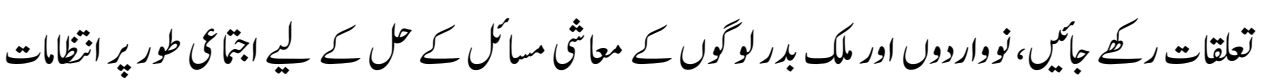

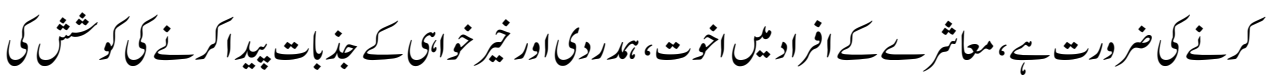

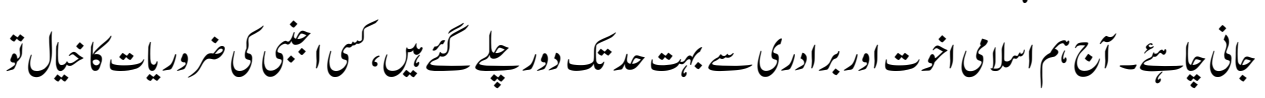

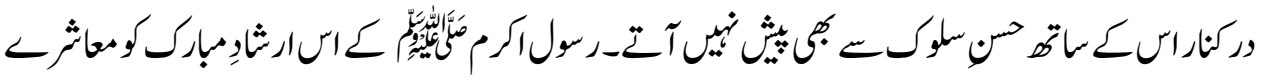

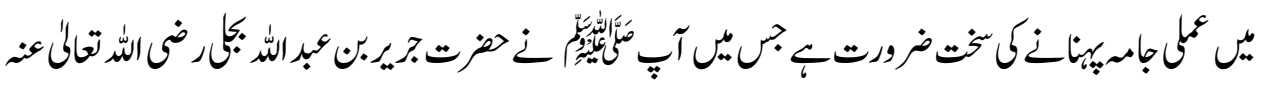
ع ارثاروفاي:

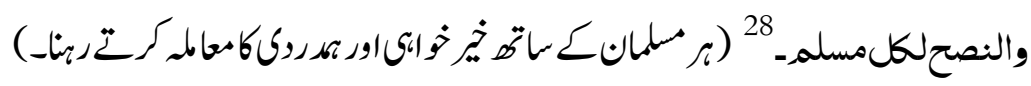

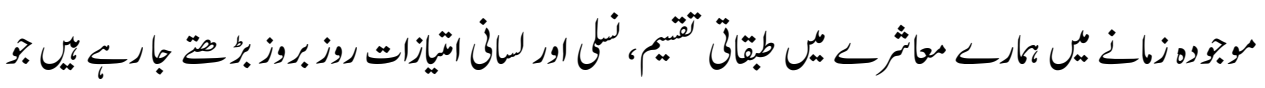

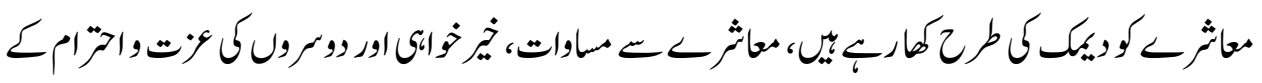

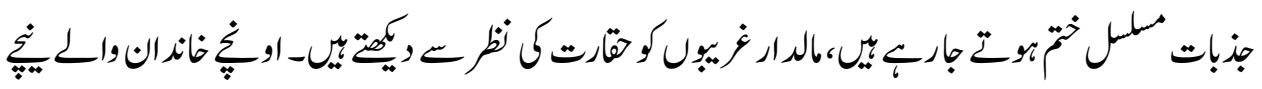

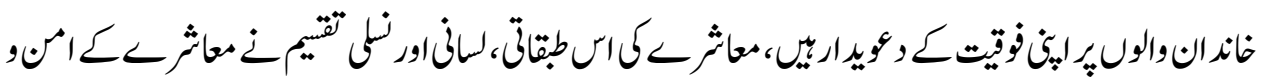

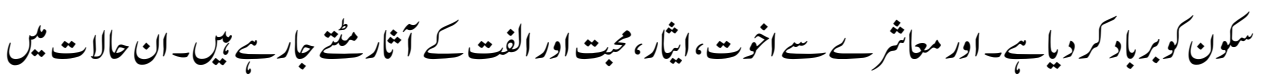

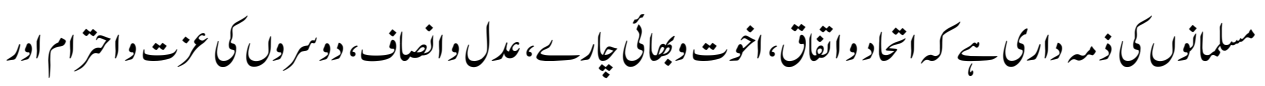

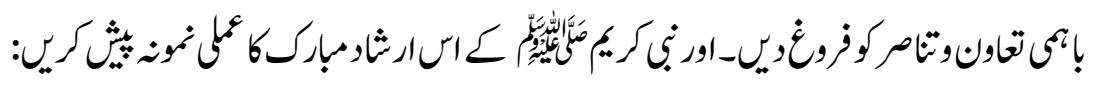




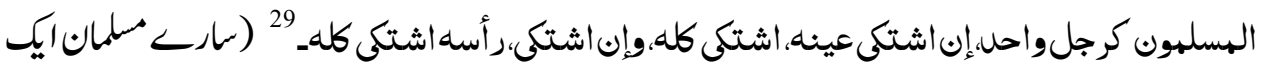

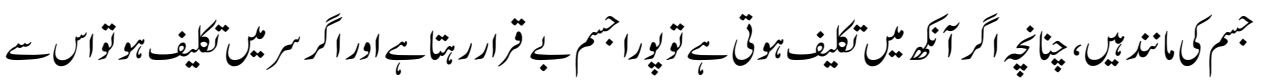

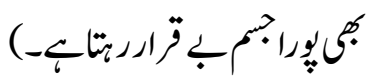

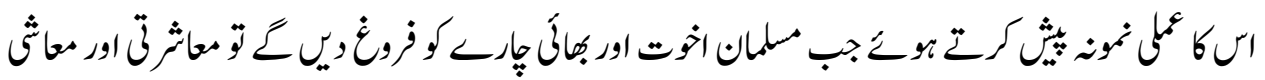

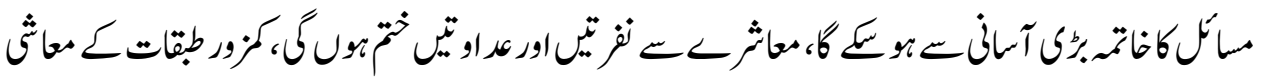

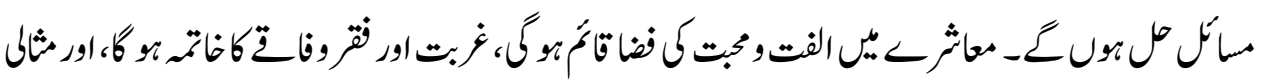

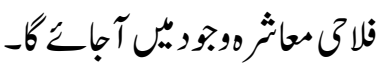
خلاص .كث:

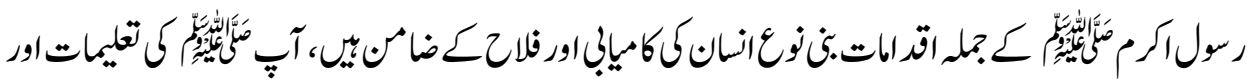

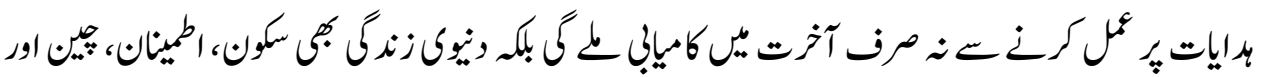

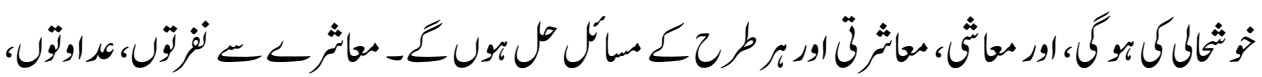

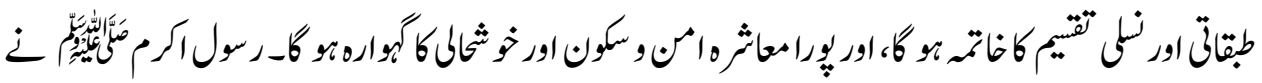

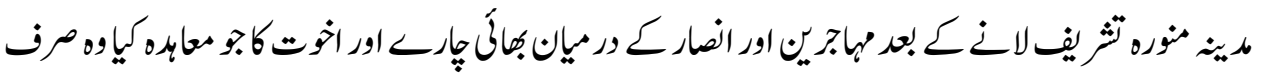

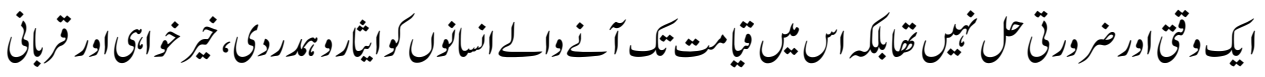

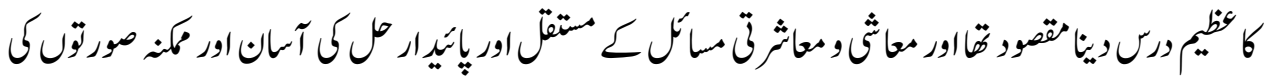

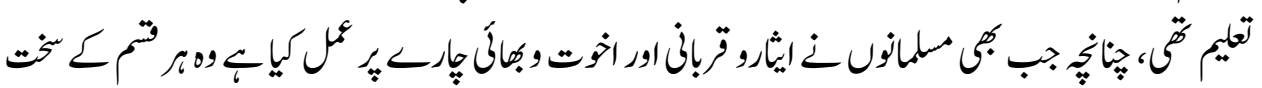

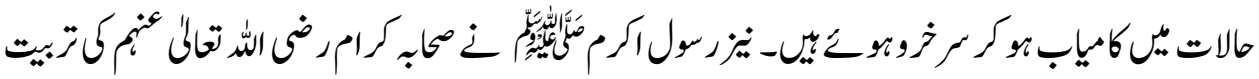

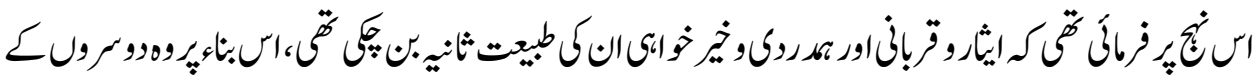

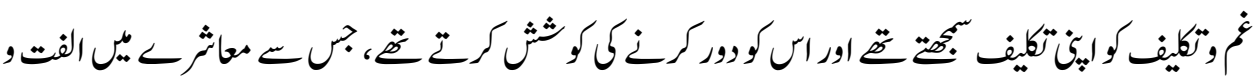

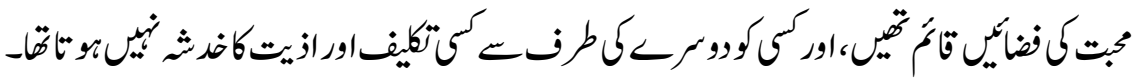

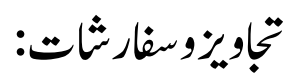

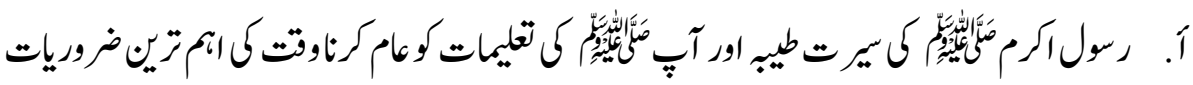




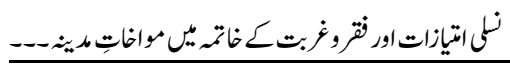

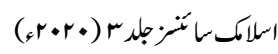

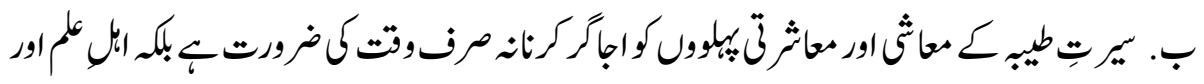

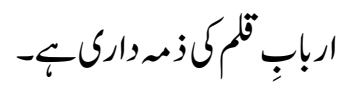

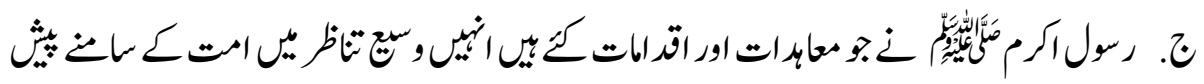

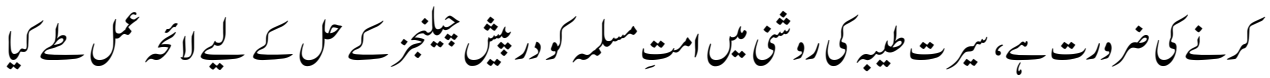

جإ

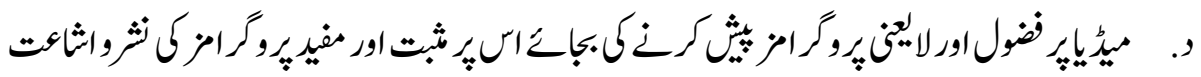

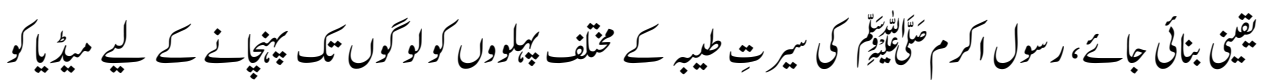

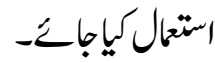

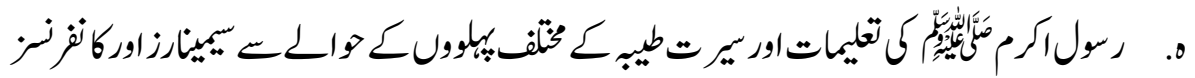

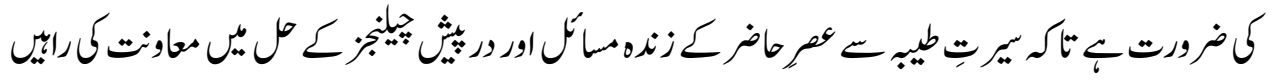

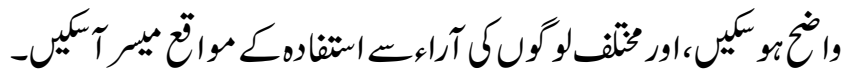

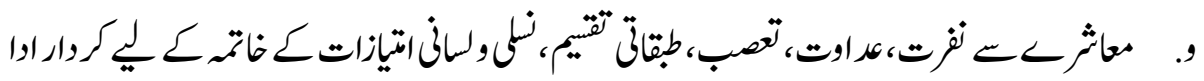

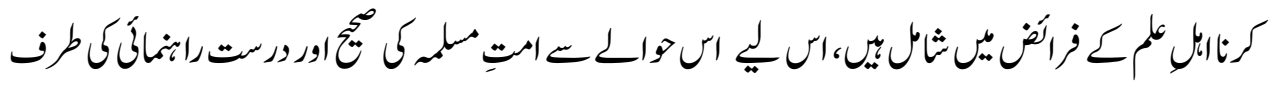

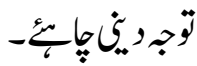

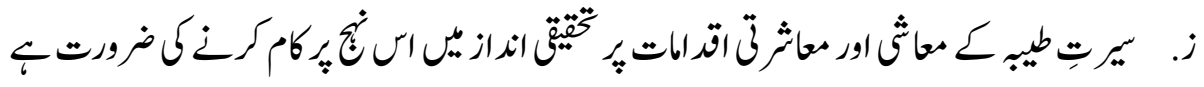

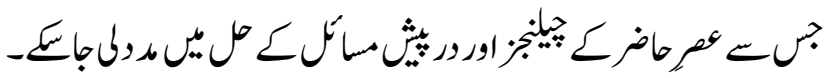

و الرجات:

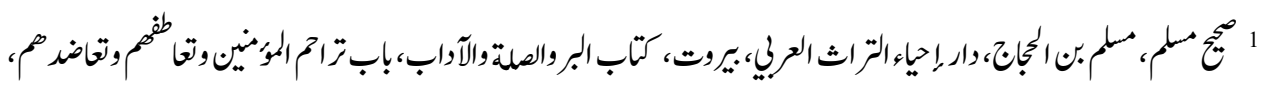

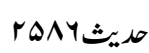

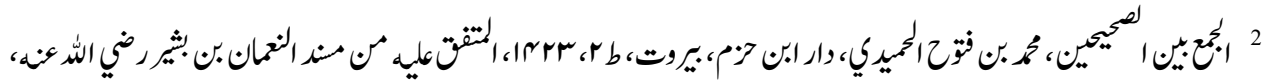

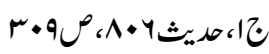

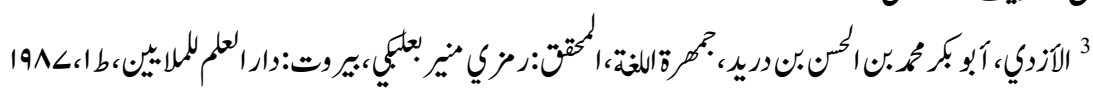

205 


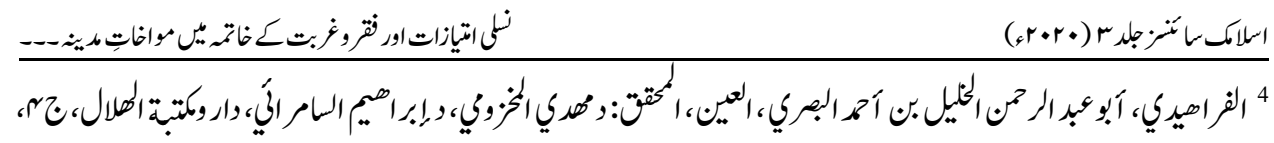

مו9

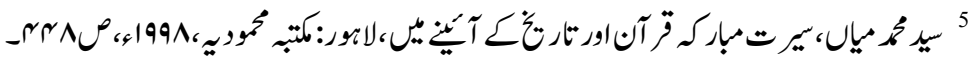

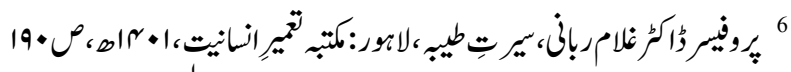

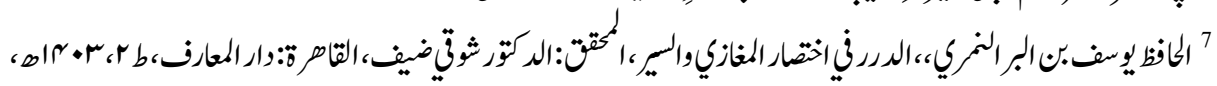
$\Lambda \Lambda \rho$

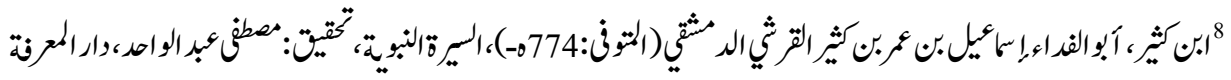

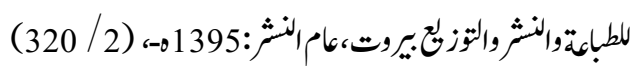

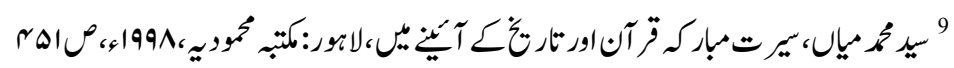

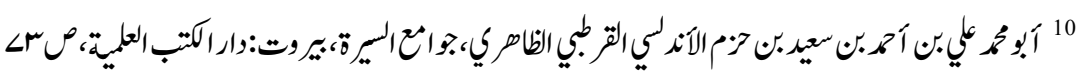

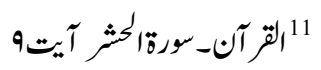

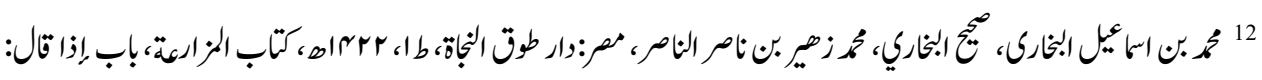

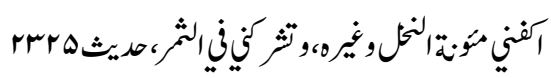

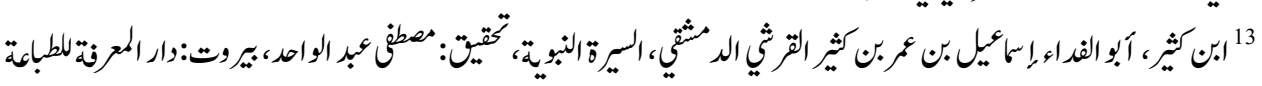

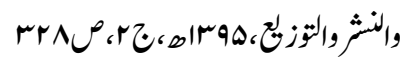
14

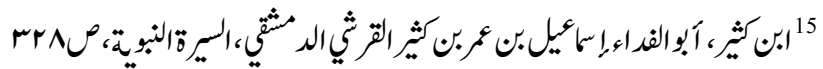

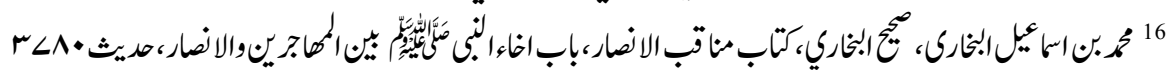

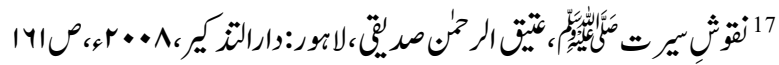

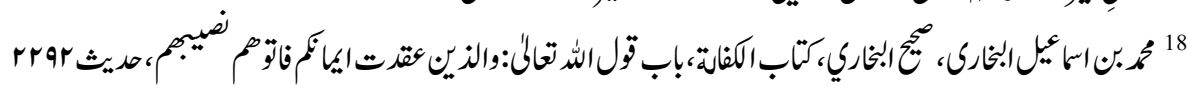

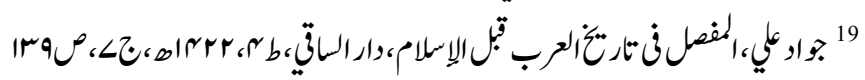

$$
20
$$

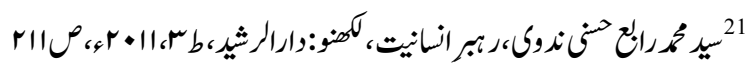
22 23

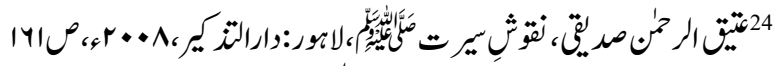

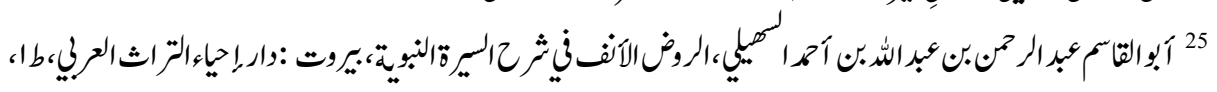
rarererererer ray 


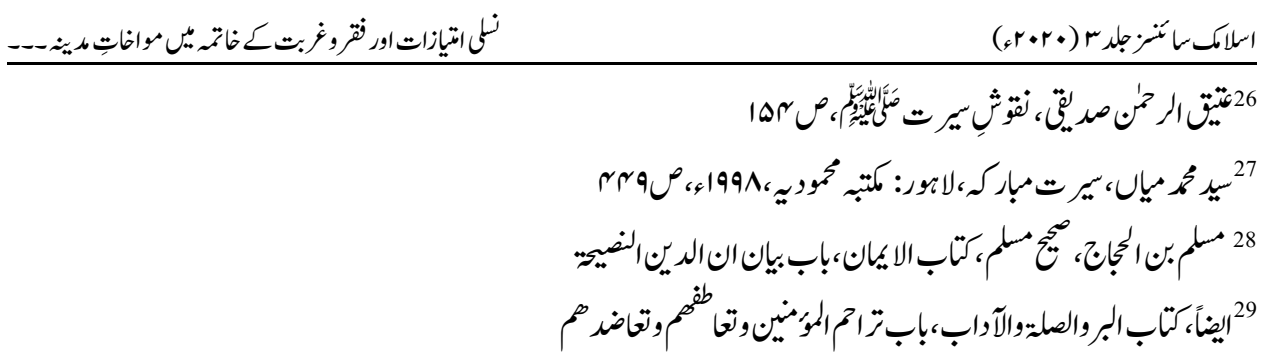

